\title{
Minimizing light absorption measurement artifacts of the Aethalometer: evaluation of five correction algorithms
}

\author{
M. Collaud Coen ${ }^{1}$, E. Weingartner ${ }^{2}$, A. Apituley ${ }^{3}$, D. Ceburnis ${ }^{4}$, R. Fierz-Schmidhauser ${ }^{2}$, H. Flentje ${ }^{5}$, J. S. Henzing ${ }^{6}$, \\ S. G. Jennings ${ }^{4}$, M. Moerman ${ }^{3}$, A. Petzold ${ }^{7}$, O. Schmid ${ }^{8,9,}{ }^{*}$, and U. Baltensperger ${ }^{2}$ \\ ${ }^{1}$ MeteoSwiss, Aerological Station, Les Invuardes, 1530 Payerne, Switzerland \\ ${ }^{2}$ Laboratory of Atmospheric Chemistry, Paul Scherrer Institut, 5232 Villigen PSI, Switzerland \\ ${ }^{3}$ National Institute for Public Health and the Environment, Bilthoven, The Netherlands \\ ${ }^{4}$ School of Physics / Environmental Change Institute, National University of Ireland, Galway; Ireland \\ ${ }^{5}$ Deutscher Wetterdienst (DWD), Meteorologisches Observatorium (MOHP), Albin-Schwaiger-Weg 10, 82383 \\ Hohenpeissenberg, Germany \\ ${ }^{6}$ Netherlands Organisation for Applied Scientific Research, TNO, 80015 Utrecht, The Netherlands \\ ${ }^{7}$ Institut für Physik der Atmosphäre, Deutsches Zentrum für Luft- und Raumfahrt, 82234 Wessling, Germany \\ ${ }^{8}$ Helmholtz Zentrum München, German Research Center for Environmental Health, Institute of Lung Biology and Disease, \\ 85758 Neuherberg/Munich, Germany \\ ${ }^{9}$ Missouri University of Science and Technology, Center of Excellence for Aerospace Particulate Emissions Reduction \\ Research, Rolla, MO 65409, USA \\ *formerly at: Max Planck Institute for Chemistry, Biogeochemistry Department, 55020 Mainz, Germany
}

Received: 1 July 2009 - Published in Atmos. Meas. Tech. Discuss.: 28 July 2009

Revised: 12 March 2010 - Accepted: 22 March 2010 - Published: 13 April 2010

\begin{abstract}
The aerosol light absorption coefficient is an essential parameter involved in atmospheric radiation budget calculations. The Aethalometer (AE) has the great advantage of measuring the aerosol light absorption coefficient at several wavelengths, but the derived absorption coefficients are systematically too high when compared to reference methods. Up to now, four different correction algorithms of the $\mathrm{AE}$ absorption coefficients have been proposed by several authors. A new correction scheme based on these previously published methods has been developed, which accounts for the optical properties of the aerosol particles embedded in the filter. All the corrections have been tested on six datasets representing different aerosol types and loadings and include multi-wavelength $\mathrm{AE}$ and white-light $\mathrm{AE}$. All the corrections have also been evaluated through comparison with a MultiAngle Absorption Photometer (MAAP) for four datasets lasting between 6 months and five years. The modification of the wavelength dependence by the different corrections is analyzed in detail. The performances and the limits of all $\mathrm{AE}$ corrections are determined and recommendations are given.
\end{abstract}

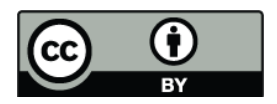

Correspondence to: M. Collaud Coen (martine.collaud@meteoswiss.ch)

\section{Introduction}

The single scattering albedo $\omega_{0}$ and the extinction Ångström exponent of atmospheric aerosol particles are needed in models calculating aerosol radiative forcing. These parameters can be determined from concomitant multi-wavelength measurements of aerosol scattering and absorption coefficients. Instruments and methods to measure the light absorption by atmospheric particles have been described in detail elsewhere (Bohren and Huffman, 1983; Horvath, 1993; Heintzenberg et al., 1997; Moosmüller et al., 1997; Bond and Bergstrom, 2006). Among the direct measurement methods, filter-based instruments have been widely used both at ground sites and on airborne platforms due to their ease of operation. However, most of the filter-based absorption techniques, which determine the aerosol absorption coefficient from the attenuation of light passing through an aerosol-laden filter, suffer from various systematic errors that need to be corrected ( $\mathrm{Li}$ ousse et al., 1993; Petzold et al., 1997; Bond et al., 1999): firstly, attenuation is enhanced by multiple scattering by the filter fibers which increases the optical path (multiple scattering correction); secondly, light attenuation is further enhanced due to scattering of aerosols embedded in the filter (scattering correction); and thirdly, attenuation is gradually

Published by Copernicus Publications on behalf of the European Geosciences Union. 
increased by the light absorbing particles accumulating in the filter thus reducing the optical path for a loaded filter (filterloading correction).

The most frequently used filter-based commercial instruments to measure real-time black carbon (BC) mass concentrations are the Aethalometer (AE) and the Particle Soot Absorption Photometer (PSAP). The multi-wavelength AE measures at seven wavelengths covering the ultra-violet to the near-infrared wavelength range (the AE-31 measures in the range from $\lambda=370$ to $950 \mathrm{~nm}$ ), the multi-wavelength PSAP has only recently become commercially available and measures at three wavelengths $(\lambda=467$ to $660 \mathrm{~nm})$. The absorption data from both instruments need to be corrected for the above mentioned artifacts in the filter matrix and these corrections require concomitant scattering measurements. In contrast to the AE and PSAP, the more recently developed Multi-Angle Absorption Photometer (MAAP) detects not only the transmitted, but also the backscattered light at two angles to resolve the influence of light-scattering aerosol components on the angular distribution of the backscattered radiation. The absorption coefficient at $\lambda=630 \mathrm{~nm}$ is thereafter obtained from a radiative transfer scheme (Petzold and Schönlinner, 2004; Petzold et al., 2005). This technique treats the multiple scattering in the filter and the scattering effect of the particles embedded on the filter. Hence, the MAAP instrument does not use any empirically determined, aerosol-related correction factors. The instrumental artifacts are reduced for the MAAP in comparison with AE or PSAP, so that the absorption coefficients measured with a MAAP should be closer to the true ones. Even if the MAAP is not an absolute reference method, it is however used as a reference for $\mathrm{AE}$ in this paper.

Various correction schemes have been published for the PSAP (Bond et al., 1999; Virkkula et al., 2005a) taking into account the above mentioned artifacts, and particularly the scattering correction. Similarly, AE correction methods presented in the literature also take these effects into account (Weingartner et al., 2003; Arnott et al, 2005; Schmid et al., 2006; Virkkula et al., 2007).

Using the above mentioned correction methods, high instrument correlation but with highly variable regression slopes were found for intercomparison measurements with various absorption instruments both in the laboratory and under atmospheric conditions (Arnott et al., 2005; Saathoff et al., 2003; Schmid et al., 2006; Wallace, 2005; Rice, 2004; Petzold et al., 2005; Virkkula et al., 2005a, b; Schnaiter et al., 2005; Park et al., 2006; Slowik et al., 2007). For example, the intercomparison of continuously operated Aethalometers, MAAPs and Photoacoustic spectrometers (PAS) at the Fresno Supersite (Park et al., 2006) resulted in regression slopes between 0.2 and 2 . The intercomparison also pointed out differences between winter and summer measurements indicating that the aerosol composition also plays an important role for instrument correlation.
It is widely accepted (Arnott et al., 2005; Schmid et al, 2006; Rice, 2004) that the uncorrected AE measures too high absorption coefficients. Weingartner et al. (2003), Arnott et al. (2005) and Schmid et al. (2006) published AE corrections, taking into account either results of chamber experiments involving extinction and scattering coefficient measurements or comparison with a PAS. The ability to correct the AE and/or PSAP for all of the above mentioned instrumental artifacts is important: firstly, to derive climatically important aerosol parameters more accurately from a simple instrument; secondly, to take advantage of already existing long-term data sets (such as the 13-year AE dataset from the Jungfraujoch (JFJ), or the 15-year AE dataset from Mace Head (MHD, see Junker et al., 2006)); and thirdly, to perform multi-wavelength measurements providing spectral information on absorption and single scattering albedo, which is not yet available from more reliable instruments.

Two new AE corrections are developed in this paper, using already published AE corrections schemes. These new corrections as well as all the previously published ones were tested on six datasets from different sites, of which four also included a MAAP (Table 1). The analyzed absorption coefficients include aerosol measured in the Alps (Jungfraujoch, Hohenpeissenberg, HOP), in a flat region near populated and industrialized areas (Cabauw, CAB), at a coastal site (Mace Head), on a pasture site affected by biomass burning (Amazon Basin, AMA) and in a city (Thessaloniki, THE). Therefore these sites represent free tropospheric, continental, maritime, biomass burning and heavily polluted environments and are characterized by a annual mean single scattering albedo $\left(\omega_{0}\right)$ between 0.65 and 0.90 (at $\lambda=660-840 \mathrm{~nm}$ ). Comparisons with a MAAP have been performed on datasets lasting between six months and five years, so that the correlation between both absorption measurements can be established on real atmospheric aerosols during a time period long enough to study the performance of MAAP and AE instruments and associated corrections in long-term monitoring programs.

\section{Experimental}

\subsection{Measurement sites and instrumentation}

Table 1 gives the main characteristics of the used datasets. All measurement sites use the same Nephelometer and MAAP types. The three kinds of AE (AE-31, AE-16 and AE-10, AE-30 being the prototype of AE-31) work with similar filter tapes (Pallflex Q250F) consisting of non-woven polyester backed quartz filter material. The main difference in the instrumentation concerns the inlet types that sample different aerosol size fractions $\left(\mathrm{PM}_{1}, \mathrm{PM}_{10}\right.$ or TSP) at different relative humidities (from dry to ambient conditions) leading to different aerosol patterns. However, at each measuring site, all three used instruments (AE, MAAP and 
Table 1. Description of the used datasets, including the measuring sites, the instruments, time periods and brief site characteristics.

\begin{tabular}{|c|c|c|c|c|c|c|c|c|}
\hline ID & Site & description & inlet & $\mathrm{AE}$ & MAAP/PAS & Neph & $\begin{array}{l}\text { Period, } \\
\text { project }\end{array}$ & Reference \\
\hline JFJ & $\begin{array}{l}\text { Jungfraujoch } \\
46^{\circ} \mathrm{N}, 8^{\circ} \mathrm{E} \\
3580 \mathrm{~m} \text { a.s. } 1 .\end{array}$ & $\begin{array}{l}\text { Alps, } \\
\text { free troposphere, } \\
\text { PBL influence }\end{array}$ & Dried TSP & $\begin{array}{l}\text { AE-31 } \\
\lambda: 370-950 \mathrm{~nm} \\
\text { Filter: Pallflex Q250F }\end{array}$ & $\begin{array}{l}\text { MAAP } \\
\lambda: 630 \mathrm{~nm}\end{array}$ & $\begin{array}{l}\text { TSI } 3563 \\
\lambda: 450-700 \mathrm{~nm}\end{array}$ & $\begin{array}{l}3.2003- \\
12.2007 \\
\text { GAW aerosol } \\
\text { monitoring } \\
\text { program }\end{array}$ & $\begin{array}{l}\text { Baltensperger } \\
\text { et al., } 1997 \\
\text { Lugauer et al., } \\
1998\end{array}$ \\
\hline $\mathrm{CAB}$ & $\begin{array}{l}\text { Cabauw } \\
51^{\circ} \mathrm{N}, 4^{\circ} \mathrm{E} \\
-0.7 \mathrm{~m} \text { a.s. } 1 .\end{array}$ & $\begin{array}{l}\text { Plane, moderate } \\
\text { maritime, near } \\
\text { populated and } \\
\text { industrialized areas }\end{array}$ & $\begin{array}{l}\text { Before March } 2008 \text {, } \\
\text { ambient air } \mathrm{PM}_{10} \\
\text { inlet placed near the } \\
\text { instruments on a } \\
\text { platform at } 60 \mathrm{~m} \text {. } \\
\text { After March } 2008 \text {, } \\
60 \mathrm{~m} \text { inlet pipe, } \\
\mathrm{PM}_{10} \text {, followed by } \\
\text { a bundle of nafion } \\
\text { dryers. }\end{array}$ & $\begin{array}{l}\text { AE-31 } \\
\lambda: 370-950 \mathrm{~nm} \\
\text { Filter: Pallflex Q250F }\end{array}$ & $\begin{array}{l}\text { MAAP } \\
\lambda: 630 \mathrm{~nm}\end{array}$ & $\begin{array}{l}\text { TSI } 3563 \\
\lambda: 450-700 \mathrm{~nm}\end{array}$ & $\begin{array}{l}2.2008- \\
7.2008 \\
\text { CESAR }\end{array}$ & $\begin{array}{l}\text { Schaap et al., } \\
2009 \\
\text { Russchenberg } \\
\text { et al., } \\
2005\end{array}$ \\
\hline MHD & $\begin{array}{l}\text { Mace Head } \\
53^{\circ} \mathrm{N}, 10^{\circ} \mathrm{W} \\
5 \mathrm{~m} \text { a.s. } 1 .\end{array}$ & $\begin{array}{l}\text { Coastal site, with } \\
\text { prevailing marine } \\
\text { (North Atlantic) air } \\
\text { masses }>50 \% \text { of the } \\
\text { time }\end{array}$ & $\begin{array}{l}\mathrm{PM}_{1}, 15 \mathrm{~m} \text { sampling } \\
\text { line with inlet at } 10 \mathrm{~m}\end{array}$ & $\begin{array}{l}\text { AE-16 } \\
\text { White light } \\
\text { Filter: Pallflex Q250F }\end{array}$ & $\begin{array}{l}\text { MAAP } \\
\lambda: 630 \mathrm{~nm}\end{array}$ & $\begin{array}{l}\text { TSI } 3563 \\
\lambda: 450-700 \mathrm{~nm}\end{array}$ & $\begin{array}{l}1.2007- \\
12.2007\end{array}$ & $\begin{array}{l}\text { Jennings et } \\
\text { al., } 2003 \\
\text { Junker et } \\
\text { al., } 2006\end{array}$ \\
\hline $\mathrm{HOP}$ & $\begin{array}{l}\text { Hohenpeissenberg } \\
48^{\circ} \mathrm{N}, 11^{\circ} \mathrm{E} \\
985 \mathrm{~m} \text { a.s.1. }\end{array}$ & $\begin{array}{l}\text { Alpine Foothill, PBL } \\
\text { influenced, rural } \\
\text { background }\end{array}$ & $\begin{array}{l}\mathrm{PM}_{10} \text {, heated } 2{ }^{\circ} \mathrm{C} \\
\text { above ambient air }\end{array}$ & $\begin{array}{l}\text { AE-10-IM } \\
\lambda \text { : white light } \\
\text { Filter: Pallflex Q250F }\end{array}$ & $\begin{array}{l}\text { MAAP } \\
\lambda: 630 \mathrm{~nm}\end{array}$ & $\begin{array}{l}\text { TSI } 3563 \\
\lambda: 450-700 \mathrm{~nm}\end{array}$ & $\begin{array}{l}1.2005- \\
12.2005\end{array}$ & $\begin{array}{l}\text { Kaminski et } \\
\text { al., } 2006\end{array}$ \\
\hline AMA & $\begin{array}{l}\text { Amazon basin } \\
11^{\circ} \mathrm{S}, 62^{\circ} \mathrm{W} \\
235 \mathrm{~m} \text { a.s.1. }\end{array}$ & $\begin{array}{l}\text { pasture site frequently } \\
\text { affected by biomass } \\
\text { burning haze from } \\
\text { fire-assisted land } \\
\text { clearing }\end{array}$ & $\begin{array}{l}5 \mathrm{~m} \text { inlet tubing, } \\
\text { Non-dried } \mathrm{PM}_{10} \text { for } \\
\mathrm{AE} \text {, and dried } \mathrm{PM}_{1.5} \\
\text { for PAS }\end{array}$ & $\begin{array}{l}\text { AE-30 } \\
\lambda: 370-950 \mathrm{~nm} \\
\text { Filter: Pallflex Q250F }\end{array}$ & $\begin{array}{l}\text { PAS } \\
\lambda: 532 \mathrm{~nm}\end{array}$ & $\begin{array}{l}\text { TSI } 3563 \\
\lambda: 450-700 \mathrm{~nm}\end{array}$ & $\begin{array}{l}9.2002- \\
11.2002 \\
\text { LBA- } \\
\text { SMOCC }\end{array}$ & $\begin{array}{l}\text { Andreae et } \\
\text { al., } 2004 \\
\text { Schmid et } \\
\text { al., } 2006\end{array}$ \\
\hline THE & $\begin{array}{l}\text { Thessaloniki } \\
40^{\circ} \mathrm{N}, 22^{\circ} \mathrm{W} \\
25 \mathrm{~m} \text { a.s.l. }\end{array}$ & City, polluted & Ambient TSP & $\begin{array}{l}\text { AE-31 } \\
\lambda: 370-950 \mathrm{~nm} \\
\text { Filter: Pallflex Q250F }\end{array}$ & not available & $\begin{array}{l}\text { TSI } 3563 \\
\lambda: 450-700 \mathrm{~nm}\end{array}$ & $\begin{array}{l}7.2006 \\
\text { SCOUT-O3 }\end{array}$ & \\
\hline
\end{tabular}

Nephelometer) sampled aerosol from the same inlet, so that comparisons are always performed for the same size fraction and relative humidity.

The scattering and backscattering coefficients of all stations were measured by Integrating Nephelometers and corrected for the truncation error and for the non-idealities in the angular intensity distribution of the light inside the instrument according to Anderson and Ogren (1998) and Nessler et al. (2005). All the data were aggregated to hourly means.

The multi-wavelength AE's cover the 370-950 nm wavelength range, and the white-light AE's have a broad spectral range from $500 \mathrm{~nm}$ to $1100 \mathrm{~nm}$ with a peak sensitivity in the near IR at about $840 \mathrm{~nm}$ (Weingartner et al., 2003). All the AE's undergo a filter-preconditioning cycle after each tape change that exposes the filter to sampled air before the measurement starts. In rack mounted Aethalometers (AE16, AE21, AE22, AE31) the sample flows through the filter tape for a part of the preconditioning cycle only (about $3 \mathrm{~min}$ ), and the flow is diverted through a by-pass cartridge filter during most of the preconditioning cycle (G. Mocnik, Aerosol d.o.o., Magee Scientific, personal communication, 2009). This preconditioning cycle can modify the zero point of the light intensity $I_{0}$ (see Eq. 1 below) and consequently the attenuation ATN. The ATN modification will change the filter loading correction and induce a lower calibration constant $C_{\text {ref }}$ for the multiple scattering correction that was estimated to less than $5 \%$ for the studied datasets. As also stated in Arnott et al. (2005), this is normally not an issue for ambient measurements as reported in this study, but it could be an issue when sampling from highly polluted sources. A better quantification of this effect is however not possible since the shift of the zero point of the filter transmittance is presently not known.

\subsection{Aethalometer corrections}

All the already published corrections are summarized in this section and the mentioned equations report only the final applied corrections. To enable a better comprehension of all corrections proposed, Table 2 lists all the used parameters, their units, a brief description and the corresponding parameters used in the previously published correction schemes, and Fig. 1 schematically describes the new correction scheme. In the following, some formal definitions are first given. 
Table 2. Symbols, units, description of the parameters used in this paper as well as the corresponding symbols used in the papers describing the previously published correction schemes. The used nomenclature follows symbols commonly used by Seinfeld and Pandis (1998).

\begin{tabular}{|c|c|c|c|}
\hline Symbol & Units & Name and function & $\begin{array}{l}\text { Corresponding symbols in } \\
\text { other papers }\end{array}$ \\
\hline$\alpha$ & & Parameter for the Arnott scattering correction & $\begin{array}{l}\alpha \text { in Arnott } \\
m_{s} \text { in Schmid } \\
s \text { in Virkkula }\end{array}$ \\
\hline$\alpha_{\text {new }}$ & & Parameter for the new scattering correction & \\
\hline$\stackrel{\circ}{a b s}_{\mathrm{abs}}$ & & Absorption Ångström exponent. It describes the wavelength dependence of $b_{\mathrm{abs}}$. & $\begin{array}{l}\alpha \text { in Weingartner } \\
\alpha_{a} \text { in Schmid }\end{array}$ \\
\hline$\stackrel{\circ}{\text { scat }}$ & & Scattering Ångström exponent. It describes the wavelength dependence of $b_{\text {scat }}$. & $\alpha_{s}$ in Schmid \\
\hline$\stackrel{\circ}{a}_{\text {scat,non-abs }}$ & & Scattering Ångström exponent for Arnott ammonium sulfate aerosol experiment & $b$ in Arnott \\
\hline $\bar{a}_{\text {scat }, s, n}$ & & $\stackrel{\circ}{\text { scat }}_{\text {mean over the } \mathrm{n} \text { first measurements since a filter spot }(\mathrm{s}) \text { change }}$ & \\
\hline$A$ & $\mathrm{~m}^{2}$ & Area of the sample spot & $\begin{array}{l}A \text { in Weingartner, } \\
\text { Arnott, Schmid and Virkkula }\end{array}$ \\
\hline ATN & & Filter attenuation measured and recorded by $\mathrm{AE}$ & $\begin{array}{l}\text { ATN in Weingartner, } \\
\text { Arnott, Schmid and Virkkula }\end{array}$ \\
\hline$\beta_{\text {scat }}$ & $\mathrm{m}^{-1}$ & Proportionality constant of the wavelength power law dependence of $b_{\text {scat }}$ & $A$ in Arnott \\
\hline$\beta_{\text {scat,non-abs }}$ & $\mathrm{m}^{-1}$ & $\begin{array}{l}\text { Proportionality constant of the wavelength power law dependence of } b_{\text {scat }} \\
\text { for Arnott ammonium sulfate aerosol experiment }\end{array}$ & \\
\hline $\bar{\beta}_{\text {scat }, s, n}$ & $\mathrm{~m}^{-1}$ & $\beta_{\text {scat }}$ mean over the $\mathrm{n}$ first measurements since a filter spot (s) change & \\
\hline$b_{\mathrm{abs}}$ & $\mathrm{m}^{-1}$ & Absorption coefficient & $\begin{array}{l}b_{\text {abs }} \text { in Weingartner } \\
B_{\text {abs }} \text { in Arnott } \\
\sigma_{\text {aeth in Schmid }} \text { in } \\
\sigma_{\text {abs }} \text { in Virkkula }\end{array}$ \\
\hline$b_{\mathrm{ATN}}$ & $\mathrm{m}^{-1}$ & Attenuation coefficient measured and recorded by $\mathrm{AE}$ & $\begin{array}{l}b_{\text {ATN }} \text { in Weingartner } \\
B_{\text {aeth }} \text { in Arnott } \\
\sigma_{\text {ATN }} \text { in Schmid } \\
\sigma_{0} \text { in Virkkula }\end{array}$ \\
\hline$b_{\mathrm{ATN}, \mathrm{R} \_ \text {corrected }}$ & $\mathrm{m}^{-1}$ & Attenuation coefficient corrected only for the filter-loading artifact $R$. & \\
\hline$b_{\text {abs,ref_MAAP }}$ & $\mathrm{m}^{-1}$ & Reference absorption coefficient from MAAP & $b_{\mathrm{abs}}$ in Weingartner \\
\hline $\mathrm{BC}_{0}$ & $\mathrm{~g} \mathrm{~m}^{-3}$ & Black carbon concentration measured and recorded by $\mathrm{AE}$ & $\mathrm{BC}_{0}$ in Virkkula \\
\hline$b_{\text {scat }}$ & $\mathrm{m}^{-1}$ & Scattering coefficient & $\begin{array}{l}b_{s} \text { in Weingartner } \\
B_{\text {sca }} \text { in Arnott } \\
\sigma_{s} \text { in Schmid } \\
\sigma_{\text {SP }} \text { in Virkkula }\end{array}$ \\
\hline $\bar{b}_{\text {scat }, s, n}$ & $\mathrm{~m}^{-1}$ & $b_{\text {scat }}$ mean over the $\mathrm{n}$ first measurements since a filter spot (s) change & \\
\hline$c$ & $\mathrm{~m}^{-1}$ & $\begin{array}{l}\text { Proportionality constant of the power-law dependence of } b_{\mathrm{ATN}} \\
\text { and } b_{\text {scat }} \text { for Arnott non-absorbing aerosol experiment }\end{array}$ & $c$ in Arnott \\
\hline$C_{\text {ref }}$ & & Multiple scattering correction constant & $\begin{array}{l}C \text { in Weingartner } \\
M \text { in Arnott } \\
C \text { in Schmid }\end{array}$ \\
\hline$C_{\text {scat }}$ & & Scattering correction in the Schmid method & \\
\hline$d$ & & $\begin{array}{l}\text { exponent of the power-law dependence of } b_{\mathrm{ATN}} \text { and } b_{\text {scat }} \text { for Arnott non-absorbing } \\
\text { aerosol experiment }\end{array}$ & $d$ in Arnott \\
\hline$f$ & & $\begin{array}{l}\text { Parameter estimating the slope of the } b_{\mathrm{ATN}} \text { versus ATN curve. It parameterizes the } \\
\text { Weingartner filter-loading correction }\end{array}$ & $f$ in Weingartner and Schmid \\
\hline$i$ & & Counter for the $i$ th number of filter spots. & \\
\hline$I_{0}$ & & Light intensity through a pristine portion of the filter & $\begin{array}{l}I_{0} \text { in Weingartner, Schmid } \\
\text { and Virkkula }\end{array}$ \\
\hline$I$ & & Light intensity through the loaded filter & $\begin{array}{l}I \text { in Weingartner, Schmid } \\
\text { and Virkkula }\end{array}$ \\
\hline
\end{tabular}


Table 2. Continued.

\begin{tabular}{|c|c|c|c|}
\hline Symbol & Units & Name and function & $\begin{array}{l}\text { Corresponding symbols in } \\
\text { other papers }\end{array}$ \\
\hline$k$ & & $\begin{array}{l}\text { Variable defining the proportionality between the last point of a filter spot and the } \\
\text { points of the next filter spot. It parameterizes the Virkkula filter-loading correction }\end{array}$ & $k$ in Virkkula \\
\hline$m$ & & Slope of the $\mathrm{f}$ versus $1-\omega_{0}$ curve. It parameterizes the new filter-loading correction & $a$ in Weingartner \\
\hline $\begin{array}{l}n \\
R_{A}\end{array}$ & & $\begin{array}{l}\text { Counter for the } n \text {th measurement since a filter change } \\
\text { Arnott filter-loading correction }\end{array}$ & \\
\hline$R_{\text {new }}$ & & New filter-loading correction & \\
\hline$R_{V}$ & & Virkkula filter-loading correction & \\
\hline$R_{W}$ & & $\begin{array}{l}\text { Weingartner filter-loading correction, with a fixed chosen } f \text { value chosen for the } \\
\text { whole dataset. }\end{array}$ & $R$ in Weingartner and Schmid \\
\hline SG & $\mathrm{m}^{2} \mathrm{~g}^{-1}$ & Spectral mass specific attenuation cross-section proposed by the manufacturer & $\begin{array}{l}\sigma_{\mathrm{abs}} \text { in Weingartner } \\
\text { SG in Arnott } \\
\alpha_{\mathrm{ATN}} \text { in Schmid }\end{array}$ \\
\hline$t$ & $\mathrm{~s}$ & Time & $\begin{array}{l}t \text { in Weingartner, Arnott, } \\
\text { Schmid and Virkkula }\end{array}$ \\
\hline$\tau_{a, \mathrm{fx}}$ & & Filter absorption optical depth for the filter fraction $x$ that has particles embedded in it. & $\tau_{a, \mathrm{fx}}$ in Arnott \\
\hline$V$ & $\mathrm{~m}^{3} \mathrm{~s}^{-1}$ & Volumetric flow rate & $\begin{array}{l}Q \text { in Weingartner, Schmid } \\
\text { and Virkkula } \\
V \text { in Arnott }\end{array}$ \\
\hline$\omega_{0}$ & & Single scattering albedo & $\begin{array}{l}\omega_{0} \text { in Weingartner and Schmid } \\
\omega \text { in Arnott }\end{array}$ \\
\hline$\omega_{0, \text { ref }}$ & & Single scattering albedo at a chosen reference wavelength $\lambda_{\text {ref }}$ & $\omega_{0, \text { ref }}$ in Schmid \\
\hline $\bar{\omega}_{0, s, n}$ & & $\omega_{0}$ mean over the $\mathrm{n}$ first measurements since a filter spot change & \\
\hline$\lambda$ & $\mathrm{nm}$ & Wavelength & $\begin{array}{l}\lambda \text { in Weingartner, Arnott, } \\
\text { Schmid and Virkkula }\end{array}$ \\
\hline
\end{tabular}

The light attenuation (ATN) through the aerosol-laden section of a filter spot is defined as

$\mathrm{ATN}=\ln \left(\frac{I_{0}}{I}\right)$

where $I_{0}$ is the intensity of light passing through a pristine portion of the filter and $I$ the intensity passing through the loaded filter. The particles embedded in the filter during a time interval $\Delta t$ will increase ATN, so that the $n$th measure of the aerosol attenuation coefficient $\left(b_{\mathrm{ATN}, n}\right)$ of the filtered aerosol particles is obtained from

$b_{\mathrm{ATN}, n}(\lambda)=\frac{\left(\mathrm{ATN}_{n}(\lambda)-\mathrm{ATN}_{n-1}(\lambda)\right)}{\Delta t} \cdot \frac{A}{V}$

where $A$ is the area of the sample spot and $V$ the volumetric flow rate. The corrections discussed below are then applied to infer the true aerosol absorption coefficient $b_{\mathrm{abs}, n}$ of airborne particles from $b_{\mathrm{ATN}, n}$.

Both the absorption Ångström exponent $\stackrel{\circ}{a}_{\text {abs }}$ and the scattering Ångström exponent $\stackrel{\circ}{a}_{\text {scat }}$, which refer to the wavelength dependence of the respective coefficients, were determined by fitting the measured absorption or scattering coefficients with a wavelength power-law dependence $\left(b \sim \lambda^{-\stackrel{\circ}{ }}\right)$. These Ångström exponents were used to calculate coeffi- cients at other wavelengths, such as the absorption coefficient at $\lambda=630 \mathrm{~nm}$ to allow comparison with the MAAP.

\subsubsection{The Weingartner correction}

Weingartner et al. (2003) proposed an empirical correction $R_{W}$ for the attenuation effect due to the filter-loading and determined the calibration constant $C_{\text {ref }}$ for different aerosol types produced in the AIDA aerosol chamber (at FZ Karlsruhe, Germany) to correct for the multiple scattering in the filter matrix. The resulting $n$th absorption coefficient $b_{\mathrm{abs}, n}$ is given by:

$b_{\mathrm{abs}, n}=\frac{b_{\mathrm{ATN}, n}}{C_{\mathrm{ref}} \cdot R_{w, n}}=\frac{b_{\mathrm{ATN}, n}}{C_{\mathrm{ref}} \cdot\left[\left(\frac{1}{f}-1\right) \cdot \frac{\ln \mathrm{ATN}_{n}-\ln (10 \%)}{\ln (50 \%)-\ln (10 \%)}+1\right]}$

where $C_{\text {ref }}$ is determined by first correcting $b_{\text {ATN }}$ for the filter-loading correction and then comparing it with the absorption coefficient measured simultaneously with a reference instrument $\left(b_{\mathrm{abs}, \mathrm{ref}}\right)$. Since the Weingartner filterloading correction $R_{W}$ takes $\mathrm{ATN}=10 \%$ as a reference point, $C_{\text {ref }}$ relates in this case to $\mathrm{ATN}=10 \%$ :

$C_{\text {ref }}=\frac{b_{\mathrm{ATN}}}{R_{W} \cdot b_{\mathrm{abs}, \text { ref }}}$ 


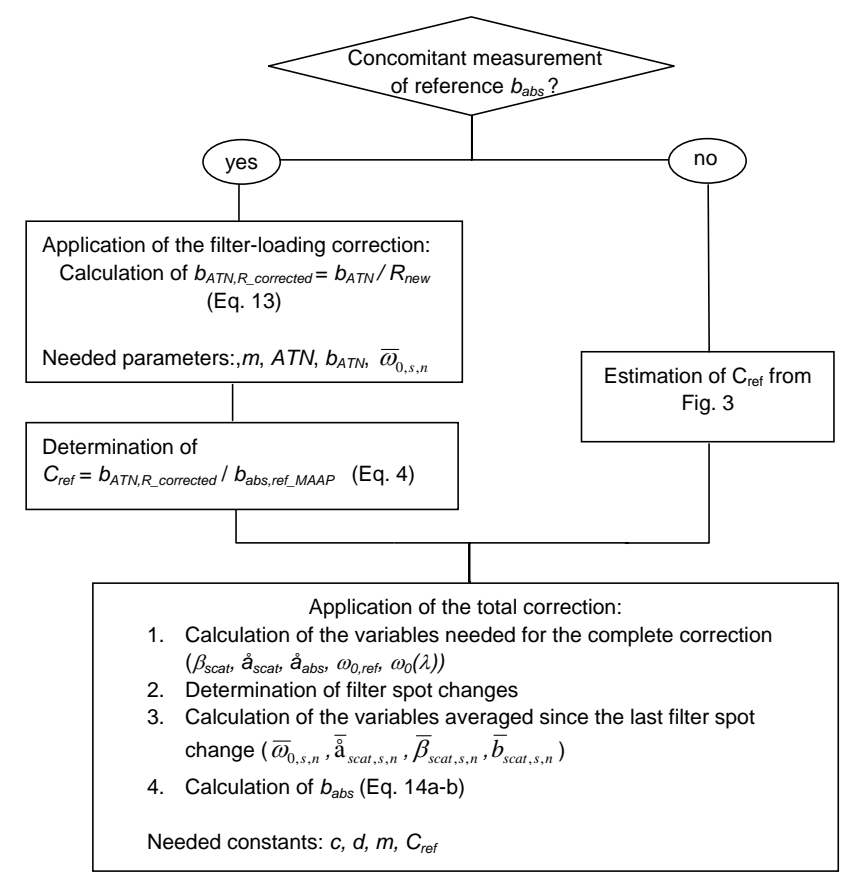

Fig. 1. Description of the sequence of steps to apply the new correction scheme.

A parameter $f(\lambda)$ is introduced which characterizes the slope between $b_{\mathrm{ATN}, n}$ and $\ln \left(\mathrm{ATN}_{n}\right)$ and parameterizes the filterloading correction $R_{W}$. A clear dependence of $f$ on $1-\omega_{0}$ was also observed for pure, internally and externally mixed diesel soot particles, which leads to the following quasilinear relation

$f=m \cdot\left(1-\omega_{o}\right)+1$,

where $m$ is nearly constant $(0.87$ to 0.85$)$ for $\lambda=470$ to $660 \mathrm{~nm}$.

The Weingartner correction parameter $R_{W}$ can depend on the light wavelength, but $C_{\text {ref }}$ does not. Therefore, a constant $C_{\text {ref }}$ value over the wide spectral range $(370-950 \mathrm{~nm})$ was chosen. Weingartner et al. (2003) also determined $f$ values for different aerosol types. In this paper, $R_{W}$ will always correspond to the Weingartner correction with fixed $f$ values chosen for each dataset depending on the aerosol type, as it is presently applied by most users, so that the $R_{W}$ correction does not need concomitant $b_{\text {scat }}$ measurements once $f$ has been determined. It is evident from Eqs. 3 through 5 that if $\omega_{0}=1$, both $f$ and $R_{W}$ are equal to unity. Since the aerosol measured at the high alpine site JFJ was aged aerosol with $\omega_{0}$ values mostly close to unity, $R_{W}$ can be taken as unity.

\subsubsection{The Arnott correction}

Arnott et al. (2005) proposed a theoretically well documented correction, which includes an explicit scattering correction similarly to the correction commonly applied to the
PSAP (Bond et al., 1999). The form of this scattering correction $\left(-\alpha \cdot b_{\text {scat }}\right)$ was deduced from the non-zero $b_{\mathrm{ATN}}$ measured by an $\mathrm{AE}$ with a purely scattering aerosol. The scattering coefficient $b_{\text {scat }}$ weighted by the $\alpha$ values was therefore subtracted from $b_{\mathrm{ATN}}$ to correct for the scattering artifact (Eq. 6). The Arnott filter-loading correction $R_{A}$ was derived from multiple scattering theory, which shows that the exponential behavior of light absorption in the strong multiple scattering limit scales as the square root of the total absorption optical depth. The corrected $b_{\mathrm{abs}, n}$ is given by :

$$
\begin{aligned}
b_{\mathrm{abs}, n} & =\frac{b_{\mathrm{ATN}, n}-\alpha \cdot b_{\mathrm{scat}, n}}{C_{\mathrm{ref}} \cdot R_{A, n}} \\
& =\frac{b_{\mathrm{ATN}, n}-\alpha \cdot b_{\mathrm{scat}, n}}{C_{\mathrm{ref}}} \sqrt{1+\frac{\left(\frac{V \cdot \Delta t}{A}\right) \cdot \sum_{i=1}^{n-1} b_{\mathrm{abs}, i}}{\tau_{a, f x}}} \\
\alpha(\lambda) & =\beta_{\mathrm{scat}, \text { non-abs }}^{d-1} \cdot c \cdot \lambda^{-\stackrel{\circ}{s c a t}, \text { non }-\mathrm{abs} \cdot(d-1)}
\end{aligned}
$$

where $n, V, \Delta t$, and $A$ were introduced in Eq. 2, $\beta_{\text {scat,non-abs }}$ and $\stackrel{\circ}{a}_{\text {scat,non-abs }}$ are obtained from measurements of ammonium sulfate aerosol and correspond to the power-law fit of the wavelength dependence of $b_{\text {scat,non-abs: }}$ :

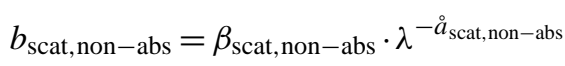

$c$ and $d$ are also obtained from the measured non-zero $b_{\mathrm{ATN}}$ in the presence of a non-absorbing aerosol and correspond to the relation between $b_{\text {scat,non-abs }}$ and $b_{\mathrm{ATN}}$ :

$b_{\mathrm{ATN}}=c \cdot b_{\text {scat,non-abs }}^{d}$

and $\tau_{a, f x}(\lambda)$ is the filter absorption optical depth for the filter fraction $x$ that has particles embedded in it, and $C_{\text {ref }}$ is obtained by comparison between AE and PAS absorption coefficients. $\tau_{a, f x}(\lambda)$ and $C_{\text {ref }}(\lambda)$ were determined from kerosene soot measurements during the Reno Aerosol Optics Experiment, under the condition that $b_{\text {abs }}(\lambda)$, when extrapolated to $\lambda=532 \mathrm{~nm}$ with $\stackrel{\circ}{a}_{\mathrm{abs}}=1$, were all equal to PAS measurements at $\lambda=532 \mathrm{~nm}$. In this Arnott correction, all the reported calibration constants depend on the wavelength of the light. Six weeks of ambient measurements at an urban site allowed testing of the proposed correction, which showed that different values of the above described parameters are needed for ambient and laboratory generated aerosol. Arnott et al. (2005) also hypothesized that the variation in these parameters is related to the $\mathrm{AE}$ pre-conditioning cycles that blackened the filters before the measurement began.

\subsubsection{The Schmid correction}

Schmid et al. (2006) proposed a correction that includes firstly the filter-loading correction $R_{W}$ with constant values of $f$ and the multiple scattering correction $C_{\text {ref }}$ developed by Weingartner et al. (2003). Secondly, comparing Arnott and Weingartner methods, they derived a new scattering correction depending on $\omega_{0}$ and the $\alpha(\lambda)$ constants derived by Arnott, which replaces the scattering correction introduced 
by Arnott. Instead of subtracting a part of $b_{\text {scat }}$ in the nominator like Arnott, the Schmid scattering correction adds a term $C_{\text {scat }}$ to $C_{\text {ref }}$, leading to a correction that includes both the multiple scattering and the scattering corrections in the denominator:

$$
\begin{aligned}
b_{\mathrm{abs}, n}(\lambda) & =\frac{b_{\mathrm{ATN}, n}}{\left(C_{\mathrm{ref}}+C_{\mathrm{scat}, n}\right) \cdot R_{W, n}} \\
& =\frac{b_{\mathrm{ATN}, n}}{\left(C_{\mathrm{ref}}+\alpha \cdot \frac{\omega_{0, n}}{1-\omega_{0, n}}\right) \cdot\left[\left(\frac{1}{f}-1\right) \cdot \frac{\ln \mathrm{ATN}_{n}-\ln (10 \%)}{\ln (50 \%)-\ln (10 \%)}+1\right]}
\end{aligned}
$$

The corrected $b_{\text {abs }}$ measured either by an AE or a PSAP were compared to the $b_{\text {abs }}$ measured by a PAS at $\lambda=532 \mathrm{~nm}$ for some days of measurements in AMA, leading to high correlations and ratios between AE and PAS $b_{\text {abs }}$ of between 0.94 and 1.03 .

\subsubsection{Virkkula filter-loading correction}

Virkkula et al. (2007) proposed a filter-loading correction $R_{V}$ very close to that of the PSAP, assuming that the three last values measured on the filter spot $i$ and the three first values measured on the next filter spot $i+1$ should be equal, and that the values measured on lightly loaded filters are the closest to the real concentration:

$$
\begin{aligned}
& b_{\mathrm{ATN}, R_{-} \text {corrected }, n}=\frac{b_{\mathrm{ATN}, n}}{R_{V}}=\left(1+k_{i} \cdot \mathrm{ATN}\right) \cdot b_{\mathrm{ATN}, n} \\
& k_{i}=\frac{\mathrm{BC}_{0}\left(t_{i+1, \text { first }}\right)-\mathrm{BC}_{0}\left(t_{i, \text { last }}\right)}{\mathrm{ATN}\left(t_{i, \text { last }}\right) \cdot \mathrm{BC}_{0}\left(t_{i, \text { last }}\right)-\mathrm{ATN}\left(t_{i+1, \text { first }}\right) \cdot \mathrm{BC}_{0}\left(t_{i+1, \text { first }}\right)}
\end{aligned}
$$

where $t_{i}$, last is the time of the last measurement on the filter spot $i$ and $t_{i+1 \text {,first }}$ is the time of the first measurement on the next filter spot $i+1$. A $k_{i}$ value is therefore determined for each filter spot and applied to all $n$ measurements on the $i$ th filter spot. The correction was validated by a comparison with simultaneous aerosol volume concentration measurements at three sites with different aerosol types.

Virkkula et al. (2007) chose to set the scattering correction to zero, since a lot of AE users do not have concomitant scattering measurements. In addition, they did not introduce a multiple scattering correction. Henceforth, the Virkkula correction will be considered as a filter-loading correction only and not as a total correction of the attenuation coefficient, since the multiple scattering correction is not negligible as will be shown below.

\subsubsection{The new correction}

The necessity of a further development of the above described corrections became obvious when the corrections were applied to the JFJ dataset (see Sects. 3 and 4). Firstly, the Weingartner filter-loading correction $R_{W}$ results in $1 / R_{W}<1$ for $\mathrm{ATN}<10 \%$. Considering that a pristine filter should produce no artifact, $1 / R_{W}$ should be equal to 1 for $\mathrm{ATN}=0$. The subtraction of $\ln (10 \%)$ was therefore removed for the new filter-loading correction. Weingartner et al. (2003) found a linear relationship between $b_{\text {ATN }}$ and $\ln (\mathrm{ATN})$, which leads to a $m$ value (Eq. 5) independent of the wavelength. Recent experiments with aged diesel soot showed a linear relationship between $b_{\text {ATN }}$ and ATN (Steiger, 2008). Investigations of the JFJ and THE datasets show that the regressions between $b_{\mathrm{ATN}}$ and ATN are statistically better than between $b_{\mathrm{ATN}}$ and $\ln (\mathrm{ATN})$. The direct proportionality is therefore chosen for the modified Weingartner filter-loading correction (Eq. 13). A new $m$ value was consequently calculated similarly to that of Weingartner et al. (2003) and with the same datasets from the AIDA chamber experiment but by fitting a linear relationship between $b_{\text {ATN }}$ and ATN. This $m$ value has a mean value $m=0.74$ when averaged over the experiments and the wavelengths, but is wavelength dependent. It was verified for all datasets that a change of the $m$ value induces a change in the calculated $C_{\text {ref }}$ but insignificant changes in the final $b_{\text {abs }}$ values. The new filter-loading correction is:

$R_{\text {new }, s, n}=\left(\frac{1}{m \cdot\left(1-\bar{\omega}_{0, s, n}\right)+1}-1\right) \cdot \frac{\mathrm{ATN}_{n}}{50 \%}+1$

where ATN is given in $\%, \bar{\omega}_{0, s, n}$ is the mean of the $n$ single scattering albedo measured since the filter spot change, where the subscript $s$ indicates that the mean optical properties of the aerosol particles embedded in the filter spot and not only of the $n$th measurement are taken into account.

Secondly, the new corrections take explicitly into account the fact that the AE measures a non-zero $b_{\text {abs }}$ when loaded with non-absorbing aerosol. Either the Arnott or the Schmid scattering correction schemes can be applied. Both corrections use the Arnott $\alpha(\lambda)$ parameters to weight the scattering correction. Following the Arnott assumption of $\alpha$ being constant for a defined $\lambda$, the ratio $b_{\text {abs }} / b_{\text {scat }}$ for nonabsorbing aerosols should be constant, independently of the value of $b_{\text {scat }}$. The 2007 EUSAAR intercomparison campaign in Leipzig showed however that the ratio between the absorption and scattering optical depth increased with decreasing scattering optical depth for all filter-based instruments (PSAP, MAAP and AE) (Müller et al., 2008). The scattering coefficient and its wavelength dependence (Eq. 8) should therefore match the measured aerosol and not the ammonium sulfate experiment involving high $\omega_{0}$ and high $\stackrel{\circ}{a}_{\text {scat }}\left(\stackrel{\circ}{\text { scat,non-abs }}_{\text {sco }}=3\right)$. The Arnott $\beta_{\text {scat,non-abs }}$ and $\stackrel{\circ}{\text { scat,non-abs }}_{\text {constants have therefore to correspond to } \beta_{\text {scat }}}$ and $\stackrel{\circ}{\text { scat }}_{\text {sc }}$ of the aerosol particles embedded in the filter spot. Therefore, the main modification introduced by the new correction is that the constant $\beta_{\text {scat,non-abs }}$ and $\stackrel{\circ}{\text { scat,non-abs }}_{\text {of }}$ Eq. 8 are replaced by a mean scattering coefficient $\bar{\beta}_{\text {scat, } s, n}$ and a mean scattering Ångström exponent $\overline{\grave{a}}_{\text {scat }, s, n}$ of the total aerosol load in the filter spot. The power-law regression between $b_{\text {ATN }}$ and $b_{\text {scat }}$ for non-absorbing aerosols (Eq. 9) can on the other hand be considered to be universal, so that the constants $c$ and $d$ can be taken from Arnott et al. (2005). This 
new $\alpha_{\text {new }, n}(\lambda)$ (see Eq. 15 below) allows one to take the real scattering properties of the measured aerosol into account and is therefore applied to both the Arnott and Schmid scattering correction schemes, leading to two new corrections. Similarly, instead of using $b_{\text {scat }, n}$ or $\omega_{0, n}$ measured simultaneously with the $n$th absorption measurement $b_{\mathrm{abs}, n}$ since a filter spot change, the mean scattering coefficient $\bar{b}_{\text {scat, } s, n}$ or the mean single scattering albedo $\bar{\omega}_{0, s, n}$ of the total aerosol loading in the filter spot are used for the Arnott scattering and for the Schmid scattering corrections, respectively.

Finally the new AE correction is described in Fig. 1 and by Eqs. $14 \mathrm{a}$ or $14 \mathrm{~b}$ depending if the Arnott or the Schmid scattering correction is applied:

$b_{\mathrm{abs}, n}(\lambda)=\frac{b_{\mathrm{ATN}, n}-\alpha_{\text {new }, s, n} \cdot \bar{b}_{\mathrm{scat}, s, n}}{C_{\mathrm{ref}} \cdot R_{\text {new }, s, n}}$

similar to Arnott

$$
\begin{aligned}
b_{\mathrm{abs}, n}(\lambda) & =\frac{b_{\mathrm{ATN}, \mathrm{n}}}{\left(C_{\mathrm{ref}}+C_{\mathrm{scat}, s, n}\right) \cdot R_{\mathrm{new}, s, n}} \\
& =\frac{b_{\mathrm{ATN}, n}}{\left(C_{\mathrm{ref}}+\alpha_{\mathrm{new}, s, n} \cdot \frac{\bar{\omega}_{0, s, n}}{1-\bar{\omega}_{0, s, n}}\right) \cdot R_{\mathrm{new}, s, n}}
\end{aligned}
$$

similar to Schmid

with the new $\alpha_{\text {new }, s, n}(\lambda)$ given by

$\alpha_{\text {new }, s, n}=\bar{\beta}_{\text {scat }, s, n}^{d-1} \cdot c \cdot \lambda^{-\bar{a}_{\text {scat }, s, n} \cdot(d-1)}$

with $d=0.564$

and $c=0.797 \cdot 10^{(-6 d)}=0.32910^{-3}, b_{\text {scat }}\left[m^{-1}\right]$

The $C_{\text {ref }}$ is determined by comparing the $b_{\text {ATN }}$ already corrected for the filter-loading with the new $R_{\text {new }}$ correction to

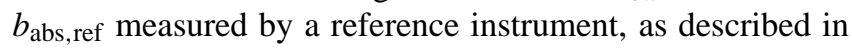
Eq. 4.

The wavelength dependent $\omega_{0}(\lambda)$ (Eq. 16) is obtained from $\omega_{0, \text { ref }}$ that can be calculated with the scattering coefficient taken at one of the AE wavelengths $\lambda_{\text {ref }}$ and the first estimation of $b_{\mathrm{abs}}=b_{\mathrm{ATN}} / \mathrm{SG}$ (Schmid et al., 2006), where SG is the mass specific attenuation cross-section proposed by the manufacturer $\left(14625 / \lambda\left[\mathrm{m}^{2} \mathrm{~g}^{-1}\right], \lambda\right.$ in $\left.[\mathrm{nm}]\right)$. It was verified with the JFJ and THE datasets that the choice of the initial wavelength $\lambda_{\text {ref }}$ is not important for the final result:

$\omega_{0}(\lambda)=\frac{\omega_{0, \text { ref }} \cdot\left(\frac{\lambda}{\lambda_{\text {ref }}}\right)^{-\stackrel{\circ}{a}_{\text {scat }}}}{\omega_{0, \text { ref }} \cdot\left(\frac{\lambda}{\lambda_{\text {ref }}}\right)^{-\stackrel{\circ}{a}_{\text {scat }}}+\left(1-\omega_{0, \text { ref }}\right) \cdot\left(\frac{\lambda}{\lambda_{\text {ref }}}\right)^{-\stackrel{\circ}{a b s}_{\text {ab }}}}$

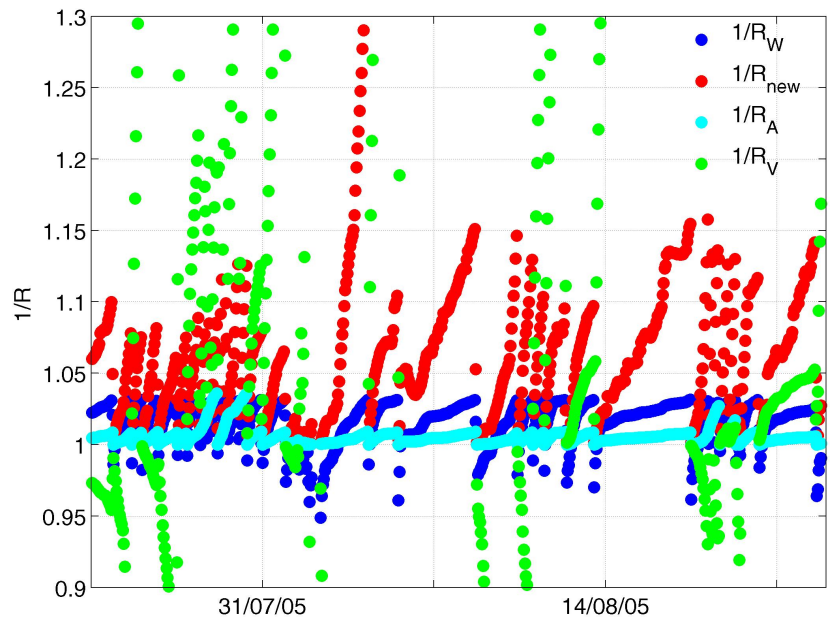

Fig. 2. $1 / R$ for the four filter-loading corrections as a function of time for about one month measured at the JFJ at $\lambda=370 \mathrm{~nm}$.

\section{Results}

\subsection{Effects of each partial correction corresponding to a systematic artifact}

\subsubsection{The filter-loading correction}

Figure 2 shows $1 / R$ calculated by the methods by Weingartner et al. (2003), Arnott et al. (2005), and Virkkula et al. (2007) as well as the new one described under 2.2.5 for one month of measurements at the JFJ, and Table 3 summarizes the results of the four $R$ corrections applied to all the datasets. The constant $f$ of the Weingartner $1 / R_{W}$ correction was estimated from Weingartner et al. (2003), with $f=1.025$ corresponding to aged mixed aerosols (JFJ, HOP) and $f=1.2$ for aerosols near pollution sources (THE), while intermediate values of $f=1.05$ and $f=1.10$ were taken for MHD and CAB, respectively. The form of the Weingartner filter-loading correction results in $1 / R_{W}<1$ for $\mathrm{ATN}<10 \%$, which leads to minimal $1 / R_{W}$ values of $0.77<1 / R_{W}<0.93$ depending on the station and consequently to an increase of $b_{\text {abs }}$ measured on lightly loaded filters. For all the analyzed datasets, the maximum of $1 / R_{W}$ amounts to 1.06 , whereas the mean of $1 / R_{W}$ varies between 1.01 and 1.03. The Arnott filter-loading correction leads to $1 / R_{A}$ values between 1 and 1.81 with mean values between 1.00 and 1.08. The new correction has a minimum $1 / R_{\text {new }}$ value of 1 similar to the Arnott correction and a maximum value of 2.56. The mean $1 / R_{\text {new }}$ values vary between 1.05 and 1.37 . The Weingartner, Arnott and the new filter-loading corrections have a clear wavelength dependence with a greater $1 / R$ at lower wavelengths, following the wavelength dependence of ATN and $b_{\text {abs. }}$. The Virkkula filter-loading correction is highly nonstable, leading to large negative and positive $1 / R_{V}$ outliers. Moreover, its wavelength dependence varies. The difficulty of applying the Virkkula correction is due to the natural high 
Table 3. Use of the scattering coefficient, minimum, maximum and mean of $1 / R$ values, for all four filter-loading corrections and for the four measuring stations. For the Weingartner correction $f=1.025, f=1.1, f=1.05, f=1.025, f=1.025$ and $f=1.2$ were taken for JFJ, CAB, MHD, HOP, AMA and THE datasets, respectively. $R$ values were taken at $\lambda=660 \mathrm{~nm}$ for multi-wavelength AE (JFJ, CAB, AMA and THE).

\begin{tabular}{|c|c|c|c|c|c|c|c|c|c|c|c|c|c|c|c|c|c|c|c|}
\hline & & & JFJ & & & $\mathrm{CAB}$ & & & MHD & & & HOP & & & AMA & & & THE & \\
\hline $\begin{array}{l}\text { Filter-loading } \\
\text { correction }\end{array}$ & $\begin{array}{l}\text { Use of } \\
b_{\text {scat }}\end{array}$ & $\begin{array}{r}\text { Min } \\
(1 / R)\end{array}$ & $\begin{array}{r}\operatorname{Max} \\
(1 / R)\end{array}$ & $\begin{array}{l}\text { Mean } \\
(1 / R)\end{array}$ & $\begin{array}{r}\text { Min } \\
(1 / R)\end{array}$ & $\begin{array}{r}\operatorname{Max} \\
(1 / R)\end{array}$ & $\begin{array}{l}\text { Mean } \\
(1 / R)\end{array}$ & $\begin{array}{r}\text { Min } \\
(1 / R)\end{array}$ & $\begin{array}{r}\operatorname{Max} \\
(1 / R)\end{array}$ & $\begin{array}{l}\text { Mean } \\
(1 / R)\end{array}$ & $\begin{array}{r}\text { Min } \\
(1 / R)\end{array}$ & $\begin{array}{r}\text { Max } \\
(1 / R)\end{array}$ & $\begin{array}{l}\text { Mean } \\
(1 / R)\end{array}$ & $\begin{array}{r}\text { Min } \\
(1 / R)\end{array}$ & $\begin{array}{r}\operatorname{Max} \\
(1 / R)\end{array}$ & $\begin{array}{l}\text { Mean } \\
(1 / R)\end{array}$ & $\begin{array}{r}\text { Min } \\
(1 / R)\end{array}$ & $\begin{array}{r}\operatorname{Max} \\
(1 / R)\end{array}$ & $\begin{array}{l}\text { Mean } \\
(1 / R)\end{array}$ \\
\hline Weingartner $R_{W}$ & no & 0.87 & 1.02 & 1.01 & 0.77 & 1.06 & 1.01 & 0.84 & 1.06 & 1.03 & 0.91 & 1.02 & 1.01 & 0.93 & 1.03 & 1.01 & 0.94 & 1.02 & 1.01 \\
\hline Arnott $R_{A}$ & no & 1.00 & 1.07 & 1.00 & 1.00 & 1.15 & 1.01 & 1.00 & 1.40 & 1.03 & 1.00 & 1.22 & 1.03 & 1.00 & 1.81 & 1.08 & 1.00 & 1.30 & 1.03 \\
\hline Virkkula $R_{V}$ & no & -250 & 1803 & 2.23 & -3.60 & 6.99 & 1.05 & -1.18 & 10.08 & 1.14 & -87 & 223 & 1.31 & -1.61 & 8.73 & 1.07 & -134 & 182 & 0.92 \\
\hline New correction $R_{\text {new }}$ & yes & 1.00 & 1.36 & 1.05 & 1.00 & 1.23 & 1.05 & 1.00 & 2.56 & 1.12 & 1.00 & 1.37 & 1.09 & 1.00 & 2.05 & 1.29 & 1.00 & 1.27 & 1.09 \\
\hline
\end{tabular}

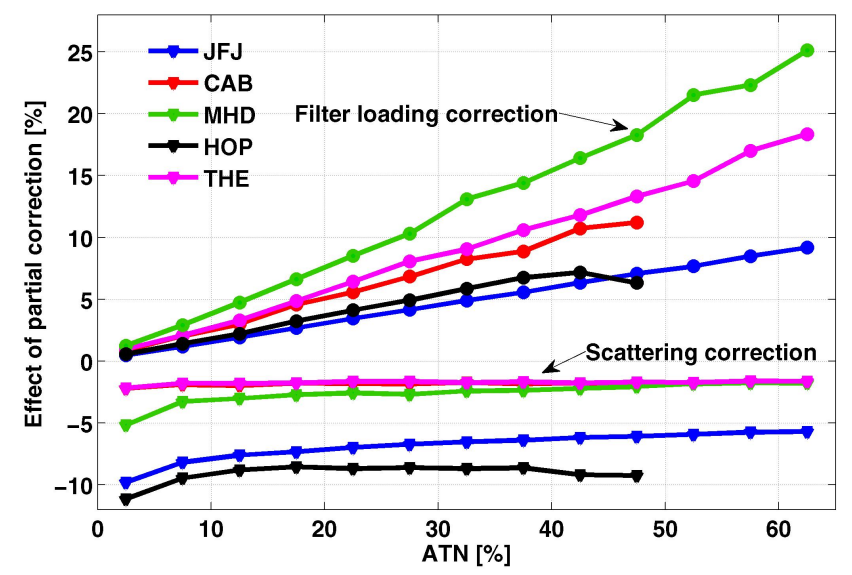

Fig. 3. Effect of the filter-loading $(\bullet)$ and of the scattering $(\boldsymbol{\Delta})$ partial corrections [(total correction - total correction without one partial correction)/total correction] as a function of the attenuation of light through the filter for 5 stations. At MHD and HOP the maximum of the wavelength is found at $840 \mathrm{~nm}$, where $\lambda=370 \mathrm{~nm}$ is reported for multi-wavelength $\mathrm{AE}$ (JFJ, CAB, THE). For the THE dataset, a $C_{\text {ref }}=4.26$ similar to the one of $\mathrm{CAB}$ was applied.

variability of $b_{\mathrm{ATN}}$ as a function of time, which is for most of the time greater than the $b_{\mathrm{ATN}}$ decrease induced by filter changes.

The filter-loading artifact can be clearly visualized after a filter change in a distinct step in $b_{\text {ATN }}$ during chamber studies, when the aerosol type and concentration remains fairly constant. In an ambient environment however, steps in $b_{\text {ATN }}$ are not only due to the filter-loading artifact but also due to the natural variability of the aerosol properties. The efficacy of the four filter-loading corrections to smooth steps in $b_{\mathrm{ATN}}$ due to the filter-loading artifact was tested on the THE and JFJ datasets, leading to no significant differences between the filter-loading corrections.

The averaged effect of the filter-loading correction is plotted in Fig. 3 as a function of ATN for the various datasets. At $\mathrm{ATN}=60 \%$ the filter loading correction increases $b_{\mathrm{abs}}$ by 7 to $25 \%$ depending on the station. The greatest filter-loading corrections are found for MHD and for the most polluted environments (THE, CAB).

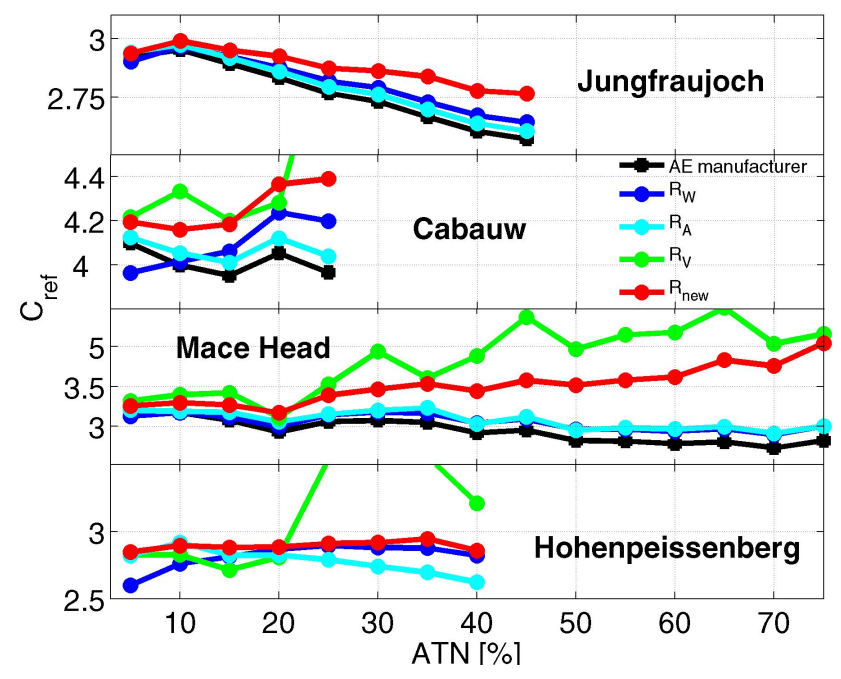

Fig. 4. $C_{\text {ref }}$ calculated from $b_{\text {abs }}$ corresponding to a defined ATN as a function of ATN for the four filter-loading corrections and for the JFJ, CAB, MHD and HOP datasets as well as for the $b_{\mathrm{abs}} \mathrm{AE}$ output calculated as recommended by the manufacturer. For JFJ and $\mathrm{CAB}, b_{\mathrm{abs}}$ at $\lambda=660 \mathrm{~nm}$ are represented. For JFJ, the Virkkula filterloading correction leads to too high $C_{\text {ref values varying between } 3.7}$ and 17 , and for HOP, the $\mathrm{AE} b_{\mathrm{abs}}$ calculated as recommended by the manufacturer leads to around 0.6; these extreme values are not shown for clarity purpose.

Since the filter-loading correction minimizes the attenuation effect due to the filter-loading, the ratio $b_{\mathrm{ATN}, R_{-} \text {corrected }} / b_{\text {abs,ref_MAAP }}$ between the filter-loading corrected absorption and a reference absorption measurement should no longer depend on ATN. Taking the MAAP as a reference absorption measurement instrument, these $b_{\mathrm{ATN}, R_{-} \text {corrected }} / b_{\text {abs,ref_MAAP ratios for all filter-loading cor- }}$ rections are plotted as a function of ATN in Fig. 4 for JFJ, $\mathrm{CAB}, \mathrm{MHD}$ and HOP datasets, and the mean and the standard deviation of $C_{\text {ref }}$ are given in Table 4. At JFJ and HOP, the new correction leads to the flattest curve between the ra-

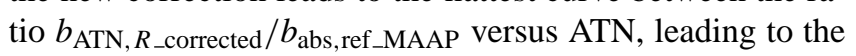
lowest standard deviations in Table 4. At CAB, the Arnott correction leads to the flattest curve, the new correction 
Table 4. Mean $C_{\text {ref }}$ constants with standard deviations for all four filter-loading corrections for JFJ, CAB, MHD and HOP stations. The correlation with the MAAP was done with $\lambda=660 \mathrm{~nm}$ at JFJ and CAB.

\begin{tabular}{lcccc}
\hline & JFJ & CAB & MHD & HOP \\
\hline Weingartner $R_{W}$ & $2.81 \pm 0.11$ & $4.09 \pm 0.12$ & $3.05 \pm 0.10$ & $2.81 \pm 0.10$ \\
Arnott $R_{A}$ & $2.80 \pm 0.13$ & $4.12 \pm 0.06$ & $3.08 \pm 0.11$ & $2.78 \pm 0.09$ \\
Virkkula $R_{V}$ & $7.77 \pm 4.15$ & $4.57 \pm 0.49$ & $3.83 \pm 0.41$ & $3.16 \pm 0.43$ \\
New correction $R_{\text {new }}$ & $2.88 \pm 0.08$ & $4.26 \pm 0.11$ & $3.51 \pm 0.23$ & $2.89 \pm 0.03$ \\
\hline
\end{tabular}

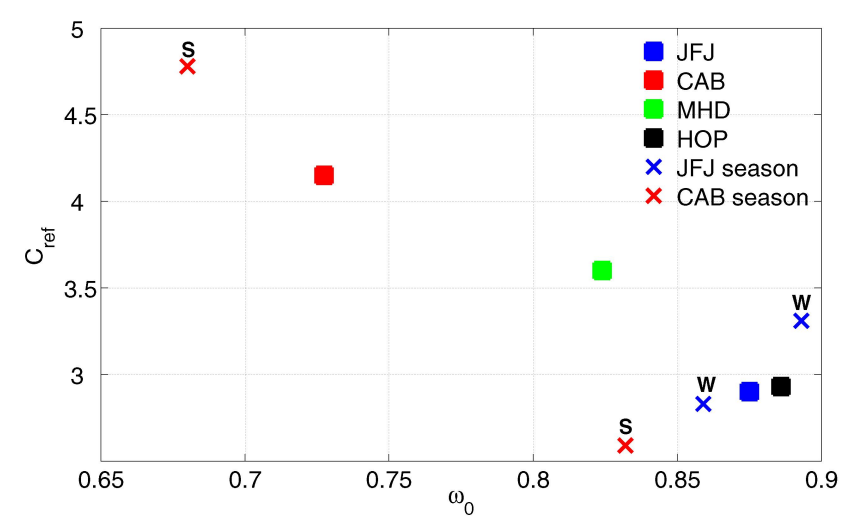

Fig. 5. $C_{\text {ref }}$ as a function of the single scattering albedo $\omega_{0}$ for the JFJ, CAB, MHD and HOP datasets. For the JFJ and CAB datasets, $C_{\text {ref }}$ and $\omega_{0}$ are also separated between summer (S) and winter (W).

having however the smallest variability with ATN for the smallest ATN. At MHD, the Weingartner and Arnott corrections are the flattest ones, the new correction becoming too large at high ATN.

\subsubsection{The multiple scattering correction}

For the evaluation of $C_{\text {ref }}$ of the multi-wavelength AE, the wavelength of $\lambda=660 \mathrm{~nm}$, which is nearest to the MAAP wavelength $(\lambda=630 \mathrm{~m})$, was chosen. The comparison of the AE and MAAP for the four datasets leads to average $C_{\text {ref }}$ values between 2.9 and 4.3 (Table 4 ) with the new filter-loading correction algorithm, while the results found with the Arnott and Weingartner filter-loading corrections are lower. Due to the particularly strong seasonal cycle of aerosol optical properties at the JFJ, an estimation of $C_{\text {ref }}$ for each month was also performed. $C_{\text {ref }}$ is lower from April to September with a mean value of 2.83, and higher during the OctoberMarch period with a mean of 3.24. The CAB dataset is too short to analyze a complete seasonal cycle. However, $C_{\text {ref }}$ is clearly higher during the May-July period than for the rest of the dataset, either because of seasonal variation of the aerosol composition or due to a modification of the inlet during March 2008 (see Table 1). HOP and MHD have less distinct seasonal cycles. Figure 5 shows $C_{\text {ref }}$ as a function of $\omega_{0}$ for the four complete datasets (squares) as well as for the JFJ and CAB datasets divided into 2 seasons. A clear correlation between $C_{\text {ref }}$ and $\omega_{0}$ exists, $C_{\text {ref }}$ becoming greater

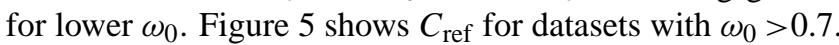
Further analysis with other ambient aerosol types, particularly in very polluted environments with lower $\omega_{0}(<0.7)$ such as big cities, should enable an extension of the results to a more universal $C_{\text {ref }}\left(\omega_{0}\right)$ curve. It is very important to establish such correlation, since the multiple scattering correction is the most important one to ensure good agreement with a reference $b_{\text {abs }}$ as will be discussed later.

According to the correction schemes, the multiple scattering artifact should depend only on the filter properties and not on the embedded aerosol. However, the calculated $C_{\text {ref }}$ is not always constant, even at the same station. This variation of $C_{\text {ref }}$ could be caused by semi-volatile organic compounds (VOCs) and water vapor condensing on the filter fibers (Weingartner et al., 2003) or to other similar phenomena such as organic particles emitted from low-temperature biomass burning that have a liquid, bead-like appearance when collected on fibrous filters (Subramenian et al., 2007). Firstly, the scattering of the filter fibers can be enhanced by these compounds, leading to a longer optical path length; secondly, the scattering phase function can also be modified leading to a modification of the mean filter reflectance; thirdly, the sticking coefficient (probability to stick on a surface) of the aerosol on the fiber and the possible change of the inter-fiber spacing can change the depth of aerosol deposition in the filter, leading to a change in its optical properties. The experimental setup used in this study does not allow us to further investigate these potential influences.

\subsubsection{The scattering correction}

The loading of the filter with scattering aerosol leads to two different artifacts: the aerosol particles scatter light in all directions, leading firstly to an increase of backscattered light and consequently to an apparent greater reflectance of the filter, and secondly to an increased light optical path and consequently to a higher probability of encountering an embedded absorbing particle. Due to its form, the applied scattering correction (subtraction of an amount proportional to the scattering coefficient) clearly corrects for an increase in the 
reflectance. The reflectance depends on the aerosol asymmetry parameter, which is lower for longer wavelengths, so that the proportionality factor $\alpha$ should increase with increasing wavelength. The second scattering artifact, as described above, leads to a higher probability of encountering an embedded particle, which is presently not compensated by any correction. The MAAP measurement technique does not correct for this second artifact either, but shows close agreement with a reference absorption measurement through the difference between light extinction and scattering (Petzold et al., 2005). This second scattering effect is therefore probably not very pronounced.

Contrary to the Arnott scattering correction, but according to recent results (Müller et al., 2008) (see Sect. 2.2.5), the new correction introduces an $\alpha_{\text {new }}(\lambda)$ that depends on $\bar{\beta}_{\text {scat }}$ and $\bar{a}_{\text {scat }}$ (Eq. 15). Figure 6a shows $\alpha_{\text {new }}$ at $\lambda=660 \mathrm{~nm}$ as a function of $b_{\text {scat }}$ for the JFJ, CAB, AMA and THE datasets. $\alpha_{\text {new }}(\lambda)$ is lower than about 0.08 for the CAB, AMA and THE datasets. When applied to the JFJ dataset, $\alpha_{\text {new }}(\lambda)$ ranges between 0 and 0.20 , but the great majority of $\alpha_{\text {new }}(\lambda)$ values are smaller than 0.1 . As expected from the wavelength dependence of the asymmetry parameter, $\alpha_{\text {new }}$ is greater at longer wavelengths. Since $\stackrel{\circ}{\text { scat }}_{\text {at }}$ AMA and THE are always near 2 (standard deviation $<0.15$ for the two stations), $\alpha_{\text {new }}$ clearly increases with decreasing $b_{\text {scat }} . \stackrel{\circ}{\text { scat }}_{\text {has a lower mean }}$ for the JFJ and CAB datasets (1.64 \pm 1.25 and $1.56 \pm 0.72$, respectively), and is much more variable, particularly at the JFJ, due firstly to the longer dataset and secondly to the presence of aged accumulation mode aerosol (Weingartner et al., 1999), which are coarser and lead to low $\stackrel{\circ}{a}_{\text {scat }}$ and sometimes even to negative $\stackrel{\circ}{a}_{\text {scat }}$ in presence of mineral particles. $\alpha_{\text {new }}$ is therefore not always increasing with $b_{\text {scat }}$, but tends towards zero for very low $\stackrel{\circ}{\text { scat }}_{\text {. }}$.

Figure 6b shows the $C_{\text {scat }}$ dependence on $\omega_{0}$ for the JFJ, CAB, AMA and THE datasets. As can be deduced from Eq. $14 \mathrm{~b}, C_{\text {scat }}$ increases with increasing $\omega_{0}$. While the $C_{\text {scat }}$ dependence on $\omega_{0}$ is well defined for the high aerosol loading at Thessaloniki, it becomes less sharp at lower aerosol concentrations, particularly at the JFJ, due firstly to a greater uncertainty in the measurement of very low $b_{\text {abs }}$ and $b_{\text {scat }}$ and secondly to a broader range of $\alpha_{\text {new }}$ values (see Fig. 5a). $C_{\text {scat }}$ maximum values can be equal to 2 for $\omega_{0}$ near one at the JFJ, but remains normally below 0.5 for most values of $\omega_{0}<0.95$. The $C_{\text {scat }}$ correction is usually greater at longer wavelengths, but inversion of this wavelength dependence is also observed.

Figure 3 shows that the new scattering correction decreases $b_{\text {abs }}$ on average by 2 to $12 \%$ depending on the station. The greatest scattering correction is obtained for the high altitude stations (JFJ, HOP) where aged aerosols are measured. Since the new scattering correction takes into account the mean scattering of all the aerosol embedded into the filter, this correction tends to be more constant with higher filter loading.

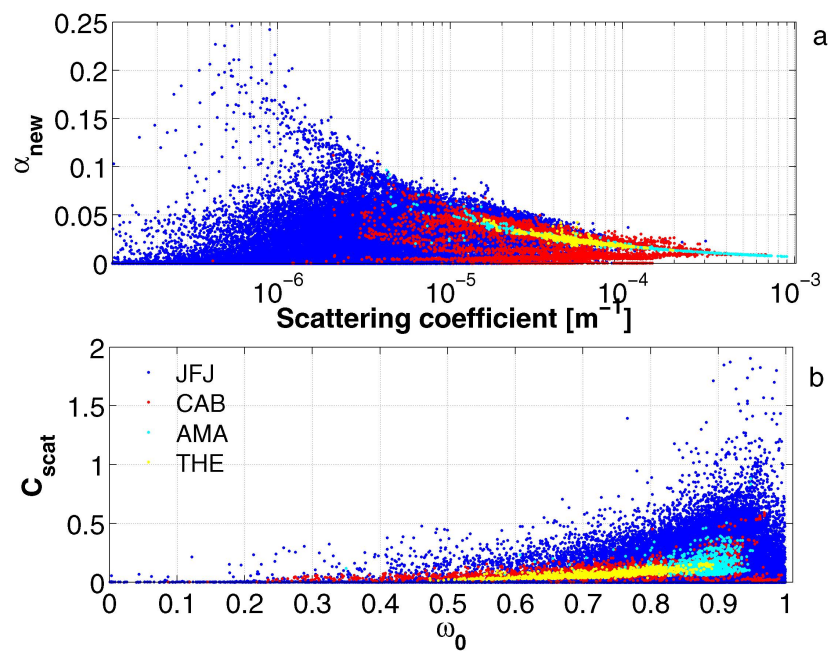

Fig. 6. Dependence (a) $\alpha_{\text {new }}$ at $\lambda=660 \mathrm{~nm}$ as a function of scattering coefficient at $\lambda=550 \mathrm{~nm}$ and (b) $C_{\text {scat }}$ as a function of $\omega_{0}$ at $\lambda=660 \mathrm{~nm}$ for the four datasets. $\alpha_{\text {new }}$ and $C_{\text {scat }}$, were calculated with the new correction scheme and represent the multiplying factor of the scattering correction (Eq. 14a), and the scattering correction in Schmid method (Eq. 14b), respectively.

\subsection{Applicability of the AE corrections}

The very low aerosol concentrations, particularly at the JFJ and MHD, induce some instrumental difficulties. Due to the fact that the measurements result from the difference between the last and the last before the last measured light attenuation through a loaded filter, very low concentrations sometimes induce negative $b_{\text {abs }}$ due to electronic noise in the raw signals (Petzold and Schönlinner, 2004). Even if negative $b_{\text {abs }}$ are not real, these values have to be kept, because they are necessary to avoid a bias in the calculated averages. The amount of negative $b_{\mathrm{abs}}$ can be lowered by use of larger flow rates or by longer integrating times. Long-term monitoring sites may however have constraints in not allowing variable integrating times. In addition, long integrating times may induce a loss of information such as, for example, diurnal cycles. Correction algorithms that can be applied to negative values are therefore necessary.

Since the Weingartner correction consists of a simple multiplication with constant factors, it can be applied to the negative values of $b_{\mathrm{abs}}$, it does not create new negative values as other algorithms do (see below), and has no impact on $\stackrel{\circ}{a}_{\text {abs }}$ (the difference between the measured and the Weingartner corrected $\stackrel{\circ}{a}_{\text {abs }}$ is less than $0.01 \%$ ), as long as $f$ is taken as a constant for a given dataset.

The Arnott correction is able to treat negative values of $b_{\text {abs. }}$. Due to the subtraction of the scattering correction, the Arnott correction often creates new negative values of $b_{\text {abs }}$. This artifact is found to be small for the shorter wavelengths ( $2.9 \%$ and $0.3 \%$ at $\lambda=370 \mathrm{~nm}$ ), but the created negative values reach up to $9.6 \%$ and $3.4 \%$ at $\lambda=950 \mathrm{~nm}$ at JFJ and CAB, respectively. The given constants $C_{\text {ref }}(\lambda)$ also yield too high 


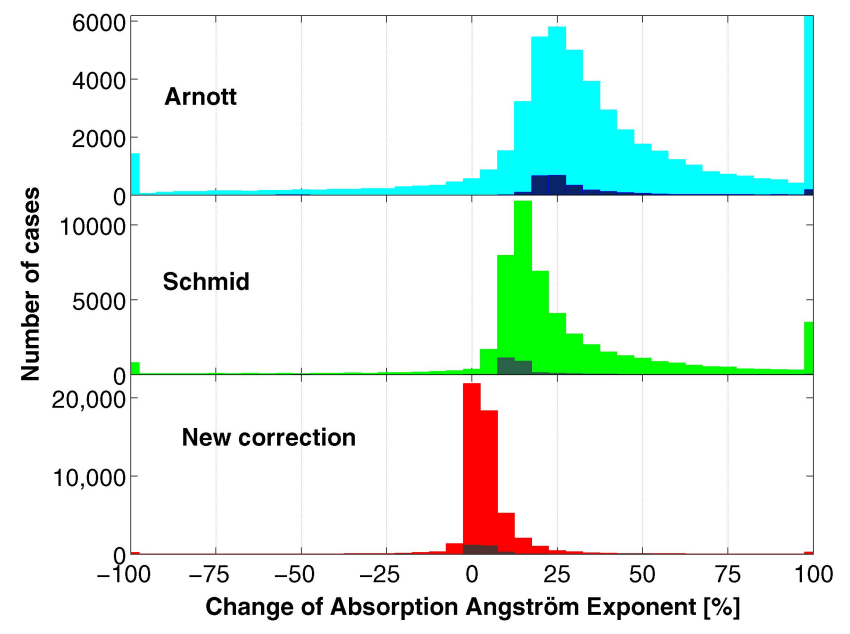

Fig. 7. Histogram of the relative change (in percent) of AE derived $\stackrel{\circ}{a}_{\text {abs }}$ values using Arnott, Schmid and the new corrections, the method similar to Schmid being represented here. The JFJ and $\mathrm{CAB}$ datasets are presented in light and dark colors, respectively. The numbers of cases represented for $\pm 100 \%$ correspond to $\stackrel{\circ}{a}_{a b s}$ changes equal or greater than $\pm 100 \%$, with values reaching sometimes up to $\pm 200 \%$ or greater.

values of $b_{\text {abs }}$. Finally, the Arnott correction has a broad impact on $\stackrel{\circ}{a}_{\text {abs }}$. As can be seen in Fig. 7, the Arnott correction produces values of $\stackrel{\circ}{a}_{\text {abs }}$ that are on average $25 \%$ higher than the initially measured ones for both datasets.

The Schmid correction depends on $\omega_{0}$; negative values of $b_{\text {abs }}$ lead to $\omega_{0}$ values greater than 1 and therefore to negative $C_{\text {scat }}$ values for the scattering correction. The use of $\stackrel{\circ}{a}_{\text {abs }}$ to calculate $\omega_{0}$ prevents its application to negative $b_{\mathrm{abs}}$. This produces new missing values of $b_{\text {abs }}(2.3 \%$ and $0.9 \%$ at JFJ and $\mathrm{CAB}$, respectively) and a few new negative values of $b_{\mathrm{abs}}$ ( $<0.1 \%$ for both datasets). The absorption wavelength dependence is also clearly modified, leading to $\stackrel{\circ}{a}_{\text {abs }}$ on average 10-15\% higher than the initially measured ones (Fig. 6) for both datasets.

The new AE corrections cannot be used for negative $b_{\mathrm{abs}}$, similarly to the Schmid correction. They therefore generate missing values unless $\stackrel{\circ}{a}_{\text {abs }}$ values are averaged in the case of negative $b_{\mathrm{abs}}$. If the new correction similar to the Arnott method (Eq. 14a) is used, new negative $b_{\text {abs }}$ values are generated $(2.1 \%$ and $<0.1 \%$ at $\lambda=370 \mathrm{~nm}$ and $2.8 \%$ and $<0.1 \%$ at $\lambda=950 \mathrm{~nm}$ at JFJ and CAB, respectively) due to the scattering correction subtraction, which is rather less than use of the Arnott correction at high wavelength values. It also introduces more outliers than the new method, similar to the Schmid method. Finally this new correction mainly preserves $\stackrel{\circ}{a}_{\text {abs }}$ (Fig. 6) with $58 \%$ and $46 \%$ of the exponents remaining constant, with $18 \%$ and $42 \%$ of the exponents having a difference of only $5 \%$, and $7 \%$ and finally $1 \%$ of the exponents having a $10 \%$ difference from the initially measured exponent at JFJ and CAB, respectively.

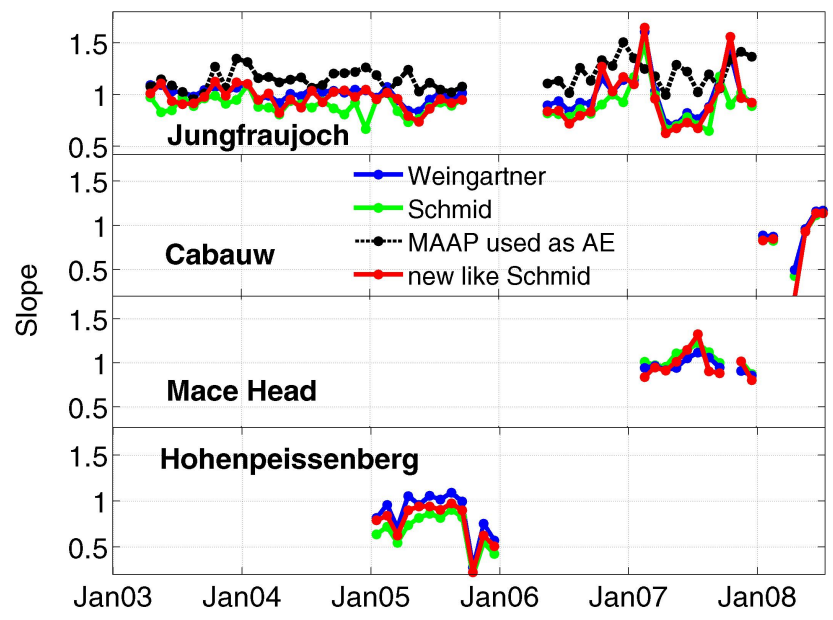

Fig. 8. Monthly regression slopes between the absorption coefficients at $\lambda=630 \mathrm{~nm}$ from the MAAP and the AE (interpolated to $\lambda=630 \mathrm{~nm}$ ) at the four stations for all the different correction schemes as well as between the absorption coefficients given by the MAAP and those measured by the MAAP in transmission only (black dashed line). For all the corrections schemes, the $C_{\text {ref }}$ values from Table 4 are applied. The lack of measurements from September 2005 to March 2006 at the JFJ is due to a leak in the MAAP inlet.

\subsubsection{Correlation of $b_{\mathrm{abs}}$ values derived from $\mathrm{AE}$ and MAAP}

As already stated in the introduction, the MAAP is not an absolute reference method for the absorption coefficient, but it has reduced the AE artifacts by using a sophisticated radiative transfer scheme. Due to its better measuring procedure and to its availability at various measurement sites for several years, the MAAP will be taken in the following as a reference to evaluate the AE corrections. The slopes of the linear regression between the corrected and the MAAP $b_{\text {abs }}$ values are reported in Fig. 8 for each month of simultaneous AE and MAAP measurements at the four stations. The averages of the monthly slopes with their standard deviations are given in Table 5. As already mentioned the Arnott correction produces a lot of outliers and has consequently very large mean slopes and is therefore not reported in Fig. 8. As can be seen in Table 5, the new correction like the Arnott and like the Schmid methods both lead to very similar results for all the stations but for JFJ, so that only the new correction like the Schmid method is reported in Fig. 7. Finally, the errors on the slope determination are always far smaller than the slope fluctuation between months, so that they have not been reported for clarity purposes.

At the JFJ, the Weingartner correction leads to higher slopes and the Schmid correction to lower slopes than the new correction. At CAB and MHD, similar slopes are found for the Weingartner, the Schmid and the new corrections. At HOP the Weingartner correction leads to the slope nearest to 
Table 5. Averages and standard deviations of the monthly slopes between MAAP $(\lambda=630 \mathrm{~nm})$ and AE (reported at $\lambda=630 \mathrm{~nm})$ absorption coefficients measured at the four stations for manufacturer estimation and each AE correction.

\begin{tabular}{lcccccc}
\hline & AE manufacturer & Weingartner & Arnott & Schmid & \multicolumn{2}{c}{ New correction similar to } \\
& & & & & Arnott (Eq. 14a) & Schmid (Eq. 14b) \\
\hline JFJ & $2.73 \pm 0.41$ & $1.00 \pm 0.15$ & - inf & $0.90 \pm 0.14$ & $1.09 \pm 1.35$ & $0.97 \pm 0.19$ \\
CAB & $3.64 \pm 0.93$ & $0.84 \pm 0.34$ & $1.77 \pm 0.59$ & $0.88 \pm 0.26$ & $0.85 \pm 0.35$ & $0.84 \pm 0.24$ \\
MHD & $2.85 \pm 0.24$ & $0.97 \pm 0.08$ & $15.2 \pm 43.7$ & $1.04 \pm 0.11$ & $0.98 \pm 0.15$ & $0.99 \pm 0.15$ \\
HOP & $2.40 \pm 0.20$ & $0.85 \pm 0.24$ & $2.48 \pm 0.71$ & $0.67 \pm 0.21$ & $0.78 \pm 0.23$ & $0.76 \pm 0.23$ \\
\hline
\end{tabular}

one, followed by the new corrections and finally the Schmid correction. At HOP and JFJ, the Weingartner, the Schmid and the new correction similar to Schmid provide similar standard deviations. At MHD, the Weingartner correction leads to the lowest standard deviation of the slopes, and the new correction to greatest ones. At CAB, the Schmid correction and the new correction similar to Schmid have the lowest standard deviations. The new correction similar to Arnott leads sometimes to higher standard deviations due to the presence of outliers.

None of the tested AE corrections are able to get rid of some time dependence of the monthly slopes such as the increase from October 2006 to February 2007 at the JFJ or the decrease in April 2008 at CAB and in October 2005 at HOP. Monthly slopes between the MAAP $b_{\text {abs }}$ output and the $b_{\text {abs }}$ measured by the MAAP in transmission only (thus using the MAAP in a similar way as the AE, i.e. without the backscattering measurements and the radiative transfer scheme, and then treated similarly to AE measurements), are also plotted in Fig. 8 (black dashed line) for the JFJ dataset. Some features such as the slope increase at the end of 2006 followed by a sharp decrease at the beginning of 2007 are also present. The variability of the monthly slopes as a function of time is therefore not only due to AE instrumental non-idealities, but also due to variations in aerosol properties. Parts of this variability might also be attributed to the condensation of VOCs, water vapor or liquid organic particles as described above. Since Arnott et al. (2005) give a prediction for a scattering correction based on aerosol scattering and asymmetry parameters, some unsuccessful attempts were performed to weight the scattering correction with the asymmetry parameters. It was also checked that monthly slopes are not correlated with the asymmetry parameter or with $\omega_{0}$.

To evaluate the influence of the filter-loading, the scattering and the multiple scattering corrections individually, the new correction was applied to the four datasets while removing successively the different components of the correction. It was found that less than three percents of the total correction is due to the filter-loading correction $R$, which was expected due to the very low mean values of $1 / R$ (Table 3 ). The greatest part of the correction is due to the multiple scattering correction, so that the $C_{\text {ref }}$ determination is the most important one to ensure a slope near unity when compared with a reference method. The difference between the Weingartner, the Schmid and the new corrections can be mainly attributed to the scattering correction. For all the four stations, the scattering correction does not have a great impact on the slope between AE and MAAP $b_{\text {abs }}$. Even if the multiple scattering correction is the largest one (150\% to $330 \%$ depending on $C_{\text {ref }}$ ) to correct for the too high $b_{\text {abs }}$ value measured by $\mathrm{AE}$, the filter-loading and the scattering corrections remain necessary since they minimize real measurable artifacts and can modify $b_{\text {abs }}$ by up to $25 \%$ on average (see Fig. 3).

\section{Discussion}

\subsection{Criteria for a good correction}

Before recommendations are formulated on the best way to correct the AE data, criteria for a good correction procedure should be stated. Firstly, the correction has to take into account all known artifacts occurring during measurements. Secondly, the correction should be applicable to all kind of datasets. Thirdly, the correction should introduce few outliers, or new missing or negative values. Fourthly, the correction should lead to the best $b_{\text {abs }}$ correlation with a "true" reference method. Fifthly, the correction should also lead to a real wavelength dependence of the $b_{\text {abs }}$ that is real $\stackrel{\circ}{a}_{\text {abs }}$. Finally, the ease of use of the correction may also be a consideration for choosing a correction method.

\subsection{Modification of the absorption Ångström exponent by $\mathrm{AE}$ corrections}

The lack of a reference measurement for $\stackrel{\circ}{a b s}_{\text {abs }}$ requires us to develop some considerations on the effects of each part of the correction on the absorption wavelength dependence. Firstly, the light absorption by aerosol loading in a filter decreases the optical path length. Since aerosol light absorption increases with decreasing wavelength, the filter-loading artifact is expected to be larger at shorter wavelengths and will decrease the absorption wavelength dependence. Secondly, the aerosol light scattering increases but the backscattered fraction decreases with decreasing wavelength. This results 
in a greater scattering coefficient but a lower reflectance at shorter wavelengths. It is therefore difficult to determine if the scattering correction for increased reflectance should modify the absorption wavelength dependence or not, and, in case of modification, if the $\stackrel{\circ}{a}_{\text {abs }}$ will be increased or decreased. Thirdly, due to increasing scattering from the particles with decreasing wavelength, the increase of the absorption due to increased probability of encountering an embedded aerosol particle should lead to an increased absorption wavelength dependence. Fourthly, since the filter fibers are non-absorbing and large (typically 1 micrometer for the quartz fiber and 10 micrometer for the cellulose fiber, Arnott et al., 2005), geometric scattering occurs from the cylindrical fibers, so that the multiple scattering correction can be expected in a first approximation to be wavelength independent and to induce no change in the absorption wavelength dependence. Weingartner et al. (2003) concluded similarly. Considering the effects of all parts of the correction on the absorption wavelength dependence, it is not possible to make precise conclusions on the expected changes of $\stackrel{\circ}{a b s}_{\text {abs }}$ induced by the AE correction.

Weingartner et al. (2003) show a high correlation between $\mathrm{AE} \stackrel{\circ}{a}_{\mathrm{abs}}$ and a reference method (measurement of the difference between extinction and scattering) for "pure" Diesel and Palas soot particles as well as soot particles externally mixed with secondary organic aerosol or ammonium sulfate; a lower correlation was found for coated soot particles. Virkkula et al. (2005a) showed a high agreement between $\stackrel{\circ}{a b s}_{a}$ from a $3 \lambda$-PSAP calculated with the Virkkula method and a reference value for $\stackrel{\circ}{a}_{\text {abs }}$ between 1.0 and 1.3. However Virkkula et al. (2005b) also concluded that the correction algorithm could still be improved regarding the wavelength dependence. A. Petzold (personal communication, 2009) showed that the $3 \lambda$-PSAP Virkkula correction (Virkkula et al., 2005b) leads to minor modification of $\stackrel{\circ}{a}_{\mathrm{abs}}$ for values around 1 but to up to 2.5 times larger $\stackrel{\circ}{a}_{\text {abs }}$ for values around 4 corresponding to desert dust. The wavelength dependence of the PSAP filter transmission is far greater than that of the AE filter, which has a low wavelength dependence (see Fig. 6 in Arnott et al., 2005). Since the reflectance of an AE filter is greater than of a PSAP filter (Arnott et al., 2005), its dependence on the scattering artifact is lower (Lindberg et al., 1999). The discrepancy between real and measured $\stackrel{\circ}{a b s}_{a}$ is therefore probably smaller for an AE than for PSAP measurements. Reviewing literature and taking into account all considerations about the modification of the absorption wavelength dependence induced by measurement artifacts, an AE correction that minimizes modifications of $\stackrel{\circ}{a}_{a b s}$ is preferred.

Both the Arnott and the Schmid corrections induce important $\stackrel{\circ}{a}_{\text {abs }}$ modifications. A finer analysis of these wavelength dependent modifications shows that they are present mostly

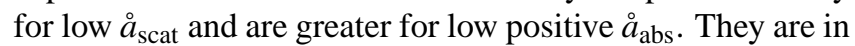
fact due to the wavelength dependence of the scattering correction constants $\alpha(\lambda)$ : since the $\alpha$ wavelength dependence is fixed for both Arnott and Schmid corrections $\left(\alpha \sim \lambda^{+1.3}\right)$, the subtracted amount of the scattering correction increases with increasing wavelength for low $\stackrel{\circ}{a}_{\text {scat }}$. The large $\stackrel{\circ}{a}_{\text {abs }}$ increase (Fig. 6) is therefore determined by the scattering properties of both non-absorbing and Diesel-soot aerosols measured by Arnott in a chamber study and cannot be explained by considerations about the wavelength dependence modification due to the scattering correction. The Weingartner correction keeps the measured $\stackrel{\circ}{a}$ abs $_{\text {absolutely unmodified for all }}$ aerosol types. The new correction similar to the Arnott or to the Schmid method mainly preserves $\stackrel{\circ}{a}_{\text {abs }}$, inducing a small increase of $\stackrel{\circ}{a}_{\text {abs }}$ in some cases, particularly in presence of mineral dust as determined for the JFJ dataset. Since no $\stackrel{\circ}{a b s}_{a}$ reference measurements are available to determine the true absorption coefficient wavelength dependence, the new correction probably offers a median solution between no modification and large modifications that are not based on theoretically or experimentally founded reasons.

\subsection{Evaluation of each $\mathrm{AE}$ correction}

Taking into account the criteria for a good correction procedure defined in Sect. 4.1, Table 6 summarizes the applicability and the performances of each $\mathrm{AE}$ correction scheme.

The AE correction proposed by Virkkula et al. (2007) does not take into account all the known artifacts and produces a lot of outliers. It is therefore not recommended to use it on atmospheric aerosol long-term datasets.

The Arnott correction (Arnott et al., 2005) proves to have technical limits mainly due to the generation of new negative $b_{\text {abs }}$ values, that are greatly enhanced at lower aerosol concentration and particularly at higher wavelengths. It introduces large ad-hoc modifications of the absorption wavelength dependence, which are not grounded in theory. The Arnott method remains therefore difficult to apply to all atmospheric aerosol datasets.

The empirical Weingartner correction (Weingartner et al., 2003 ) is easy to use, since it does not directly need $b_{\text {scat }}$ measurements, even if an evaluation of $\omega_{0}$ can influence the filterloading correction. However the determination of the $f$ constant used in the Weingartner filter-loading correction is not clearly defined. It does not modify the $\stackrel{\circ}{a b s}_{\text {abs }}$ and shows a very good agreement with the MAAP.

The Schmid correction (Schmid et al., 2006) needs concomitant scattering coefficient measurements and cannot cope with negative values of $b_{\text {abss }}$. It also introduces artifacts in the absorption wavelength dependence like the Arnott method, but to a lesser extent. It shows good agreement with the MAAP $b_{\text {abs }}$, leading however to smaller slopes than the Weingartner scheme as well as the new corrections for two stations out of the four.

Both new corrections need concomitant scattering coefficient measurements. Similarly to their originals, the new correction like Arnott generates some new negative $b_{\text {abs }}$ values and the new correction like Schmid cannot cope with 
Table 6. Evaluation of the applicability and the performance of AE corrections based on the criteria defined under Sect. 4.1.

\begin{tabular}{lcccccc}
\hline $\begin{array}{l}\text { Correction } \\
\text { Scheme }\end{array}$ & $\begin{array}{c}\text { All } \\
\text { artifacts }\end{array}$ & $\begin{array}{c}\text { Applicable to } \\
b_{\text {abs }}<0\end{array}$ & $\begin{array}{c}\text { Need } b_{\text {scat }} \\
\text { measurement }\end{array}$ & $\begin{array}{c}\text { Outliers and } \\
\text { new } b_{\text {abs }}<0\end{array}$ & $\begin{array}{c}\text { Agreement } \\
\text { with MAAP }\end{array}$ & $\begin{array}{c}\stackrel{\circ}{\text { abs }} \\
\text { modification }\end{array}$ \\
\hline Virkkula & no & yes & no & Yes & - & - \\
Weingartner & yes & yes & no & no & Very good & none \\
Arnott & yes & yes & yes & Yes, a lot & Not good & large \\
Schmid & yes & no & yes & no & good & large \\
New like Arnott & yes & no & yes & Yes, few & Very good & small \\
New like Schmid & yes & no & yes & no & Very good & small \\
\hline
\end{tabular}

negative values of $b_{\text {abs. }}$. Both new corrections introduce a small modification of $\stackrel{\circ}{a}_{\text {abs }}$ and show a very good agreement with the MAAP $b_{\text {abs }}$.

All the corrections apart from the Arnott one lead to pretty good agreements with the MAAP $b_{\text {abs }}$. The small differences in the agreement with the MAAP between the Schmid, the Weingartner and both new corrections leads to the conclusion that $C_{\text {ref }}$ is indeed the most important parameter in order to obtain a good agreement with another instrument. The scattering correction, which is achieved differently for the Weingartner, Schmid and the new corrections, has therefore a far lower impact than the multiple scattering correction. The filter-loading and the scattering corrections are however not negligible and remain necessary to correct for the welldocumented corresponding artifacts. The filter-loading correction is more important in the presence of highly polluted environments (low $\omega_{0}$ ) whereas the scattering correction is the largest in remote stations measuring aged aerosol (high $\left.\omega_{0}\right)$. For stations where no $b_{\text {abs }}$ reference measurements are available, Fig. 5 yields an estimate of $C_{\text {ref }}$ if $\omega_{0}$ is known.

The monthly slopes between AE and MAAP $b_{\text {abs }}$ vary as a function of time for all datasets with the standard deviations of the monthly slope reaching $8 \%$ to $25 \%$. Similar variations are also found as a function of other extensive and intensive aerosol parameters such as $b_{\text {scat }}, \stackrel{\circ}{a}_{\text {scat }}, \stackrel{\circ}{a b s}_{\text {abs }}$ and $\omega_{0}$. The slope between the MAAP $b_{\text {abs }}$ calculated by the MAAP software including the backscatter measurement and from the MAAP transmission measurement only (similarly to AE) are also not constant as a function of time (Fig. 7). The inter-comparison of six carbon measurement methods at the Fresno Supersite during a year (Park et al., 2006) also resulted in standard deviations of monthly values ranging between $6 \%$ and $19 \%$ of the average of all monthly values. Better results are only met for similar instruments such as two AE's. The comparison of $b_{\mathrm{abs}}$ measured by different types of instruments seems to depend always on the aerosol properties despite the presently applied corrections algorithms. Lack et al. (2008) showed that there is a correlation between the aerosol organic content (OC), ranged between 0 and $17 \mu \mathrm{g} \mathrm{m}^{-3}$, and the ratio between the $b_{\text {abs }}$ measured by a PSAP and a PAS. The aerosol OC was measured during two campaigns of 2.5 months duration at the JFJ (Cozic et al., 2007). Since the daily mean OC showed small variations and did not exceed $1.5 \mu \mathrm{g} \mathrm{m}^{-3}$ at the JFJ, no correlation between the measured $\mathrm{OC}$ and the ratio between the AE and MAAP $b_{\text {abs }}$ was found in this dataset. However, several results presented in this paper, particularly the monthly slopes presented in Fig. 8, indicate that the variability in aerosol composition is a main clue to the variable slopes between the absorption coefficients measured by the MAAP and AE instruments at the four sites.

\section{Conclusions and recommendations}

Corrections developed by Weingartner, Arnott, Schmid and Virkkula have been applied to datasets obtained from four stations with various aerosol types and loadings, two stations having a multi-wavelength $\mathrm{AE}$ and two having whitelight AE. Two new corrections based on previously published ones are also presented and are applied to the four datasets as well as to two datasets measured in the Amazon basin and in Thessaloniki. The main modifications introduced by these new corrections are firstly a new parameterization of the scattering correction, which depends on the scattering coefficient and Ångström exponent, and secondly the consideration of the optical properties of all aerosol embedded in the filter for the filter loading and for the scattering corrections. Comparisons with MAAP $b_{\text {abs }}$ were performed for all correction schemes and all four datasets. Principal criteria for a sound $\mathrm{AE}$ correction scheme were determined as to provide a good agreement with a reference instrument and to preserve $\stackrel{\circ}{a}_{\text {abs }}$, which is an important parameter measured by the multi-wavelength AE. The Arnott correction generates many new negative $b_{\text {abs }}$ at low aerosol concentrations, and it does not preserve $\stackrel{\circ}{a}_{\text {abs }}$. The Schmid correction leads to a good agreement with the MAAP, with slopes between AE and MAAP $b_{\text {abs }}$ somewhat lower than the other corrections and it does not preserve $\stackrel{\circ}{a}_{\text {abs }}$ either. The empirical Weingartner correction does not need the simultaneous $b_{\text {scat }}$ measurement; it has no application restriction for lower aerosol concentrations; it has good agreement with MAAP and it 


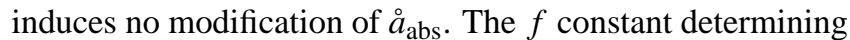
the filter-loading correction is however not well defined. The new correction scheme has also good agreement with MAAP and it mainly preserves $\stackrel{\circ}{a b s}_{\text {abs }}$ allowing however a modification of $\stackrel{\circ}{a b s}_{\text {abs }}$, for example in the case of mineral dust events. The new correction similar to the Schmid method leads to a better performance than the one similar to the Arnott method.

The results and recommendations for the AE measurements and correction algorithms are summarized as follows:

- Measured attenuation values need to be stored in databases, since they are used for all AE corrections.

- Concomitant scattering coefficient measurements are highly recommended, since they are used in all the corrections, and an estimation of the single scattering albedo $\omega_{0}$ is important in the determination of several correcting constants.

- The determination of the multiple scattering constant $C_{\text {ref }}$ is crucial to allow good agreement with MAAP data or other reference instruments' data. The analysis of data from four stations permits a first estimation of $C_{\text {ref }}$ as a function of the single scattering albedo $\omega_{0}$. Further analyses, particularly at stations with very high BC load, are however recommended prior to determining a universal correlation between $C_{\text {ref }}$ and $\omega_{0}$.

- The new filter-loading correction $R_{\text {new }}$ is the most appropriate algorithm at two stations because it leads to the most constant ratio between AE and MAAP absorption coefficients as a function of ATN.

- Modification of the absorption coefficient wavelength dependence is a very important factor issue for global radiation transfer assessments. Considerations on the wavelength dependence of each $\mathrm{AE}$ artifact does not allow to determine if an increase or a decrease of $\stackrel{\circ}{a}_{a b s}$ occurs. The use of multi-wavelength reference methods (when available) should resolve this issue.

- If no scattering coefficient measurements are available, the new correction with $\alpha_{\text {new }}=0$, which corresponds to the Weingartner correction apart from the $R$ calculation, or the Weingartner correction are recommended.

- If scattering coefficient measurements are available, the new correction procedure similar to the Schmid method is recommended.

Acknowledgements. We thank the International Foundation High Altitude Research Stations Jungfraujoch and Gornergrat (HFSJG), which made it possible for PSI to carry out the experiments at the High Altitude Research Station at the Jungfraujoch. This work was supported by MeteoSwiss within the Swiss program to the Global Atmosphere Watch (GAW) of the World Meteorological Organization. Measurements at Jungfraujoch, Mace Head and Cabauw were also supported by the EC project EUSAAR (European Supersites for Atmospheric Aerosol Research). For the measurements at Mace Head we acknowledge the Irish Environmental Protection Agency for a Senior Researcher Fellowship under the STRIVE 2007-2013 program, and for the measurements at Cabauw, we acknowledge the support of the Dutch BSIK-program. Financial support from the EC-Project SCOUT-O3 is also acknowledged. The measurements at the Amazon Basin were performed within the framework of the Smoke, Aerosols, Clouds, Rainfall, and Climate (SMOCC) project, a European contribution to the Large-Scale Biosphere-Atmosphere Experiment in Amazonia (LBA), under the leadership of M. O. Andreae and P. Artaxo. It was financially supported by the Max Planck Society (MPG) and the Environmental and Climate Program of the European Commission (contract NEVK2-CT-2001-00110 SMOCC).

Edited by: M. Wendisch

\section{References}

Anderson, T. L. and Ogren, J. A.: Determining aerosol radiative properties using the TSI 3563 integrating nephelometer, Aerosol Sci. Tech., 29(1), 57-69, 1998.

Andreae, M. O., Rosenfeld, D., Artaxo, P., Costa, A. A., Frank, G. P., Longo, K. M., and Silva-Dias, M. A. F.: Smoking rain clouds over the Amazon, Science, 303(5662), 1337-1342, 2004.

Arnott, W., Hamasha, K., Moosmüller, H., Sheridan, P. J. , and Ogren, J. A.: Towards aerosol light-absorption measurements with a 7-wavelength aethalometer: Evaluation with a photoacoustic instrument and 3-wavelength nephelometer, Aerosol Sci Tech., 39(1), 17-29, 2005.

Baltensperger, U., Gäggeler, H. W., Jost, D. T., Lugauer, M., Schwikowski, M., Weingartner, E., and Seibert, P.: Aerosol climatology at the high-alpine site Jungfraujoch, Switzerland, J. Geophys. Res., 102(D16), 19707-19715, 1997.

Bohren, C. F. and Huffman, D. R.: Absorption and Scattering by small Particles, Wiley, New York, 196, 1983.

Bond, T. and Bergstrom, R.: Light absorption by carbonaceous particles: An investigative review, Aerosol Sci. Tech., 40, 1-41, 2006.

Bond, T. C., Anderson, T. L., and Campbell, D.: Calibration and intercomparison of filter-based measurements of visible light absorption by aerosols, Aerosol Sci. Tech., 30(6), 582-600, 1999.

Cozic, J., Verheggen, B., Weingartner, E., Crosier, J., Bower, K. N., Flynn, M., Coe, H., Henning, S., Steinbacher, M., Henne, S., Collaud Coen, M., Petzold, A., and Baltensperger, U.: Chemical composition of free tropospheric aerosol for PM1 and coarse mode at the high alpine site Jungfraujoch, Atmos. Chem. Phys., 8, 407-423, 2008, http://www.atmos-chem-phys.net/8/407/2008/.

Heintzenberg, J., Charlson, R. J., Clarke, A. D., Liousse, C., Ramaswamy, V., Shine, K. P., Wendisch, M., and Helas, G.: Measurements and modeling of aerosol single-scattering albedo: progress, problems and prospects, Contrib. Atmos. Phys., 70(4), 249-263, 1997.

Horvath, H.: Atmospheric light absorption: a review, Atmos. Environ., 27(3), 293-317, 1993.

Jennings, S. G., Kleefeld, C., O’Dowd, C. D., Spain, T. G., O’Brien, P., Roddy, A. F., and O'Connor, T. C.: Mace Head Atmospheric 
Research Station - characterization of aerosol radiative parameters, Boreal Environ. Res., 8, 303-314, 2003.

Junker, C., Jennings, S. G., and Cachier, H.: Aerosol light absorption in the North Atlantic: trends and seasonal characteristics during the period 1989 to 2003, Atmos. Chem. Phys., 6, 19131925, 2006,

http://www.atmos-chem-phys.net/6/1913/2006/.

Kaminski, U., Fricke, M., Wilhelm, R., Plörer, E., Hofmann, M., and Schafranek, R.: Aerosol Measurements at the GAW Global Station Hohenpeissenberg, in: The German Contribution to the GAW Programme: Upon the 225th Anniversary of GAW Hohenpeissenberg Observatory (WMO TD No. 1336), edited by: Fricke, W., Barrie, L. A., and Schleyer, R., GAW report No. 167, 72-83, 2006.

Lack, D. A., Cappa, C. D., Baynard, T., Massoli, P., Covert, D. S., Sierau, B., Bates, T. S., Quinn, P. K., Lovejoy, E. R., and Ravishankara, A. R.: Bias in filter-based aerosol absorption measurements due to organic aerosol loading: Evidence from ambient sampling, Aerosol Sci. Tech., 42(12), 1033-1041, 2008.

Lindberg, J. D., Douglass, R. E., and Garvey, D. M.: Atmospheric particulate absorption and black carbon measurement, Appl. Optics, 38, 2369-2376, 1999.

Liousse, C., Cachier, H., and Jennings, S. G.: Optical and thermal measurements of black carbon aerosol content in different environments: Variation of the specific attenuation cross-section, sigma $(\sigma)$, Atmos. Environ., 27(8), 1203-1211, 1993.

Lugauer, M., Baltensperger, U., Furger, M., Gäggeler, H. W., Jost, D. T., Schwikoswki, M., and Wanner, H.: Aerosol transport to the high Alpine sites Jungfraujoch (3454 ma.s.1.) and Colle Gnifetti (4452 m a.s.1.), Tellus B, 50B, 76-92, 1998.

Moosmüller, H., Arnott, W. P., and Rogers, C. F.: Methods for real-time, in situ measurement of aerosol light absorption, J. Air Waste Manage., 47(2), 157-166, 1997.

Müller, T., Henzing, B., and Wiedensohler, A.: Intercomparison of three types of absorption photometers, European Aerosol Conference EAC-2008, Thessaloniki, Greece, 23-29 August 2008, T04A05P, 2008.

Nessler, R., Weingartner, E., and Baltensperger, U.: Adaptation of dry nephelometer measurements to ambient conditions at the Jungfraujoch, Environ. Sci. Technol., 39(7), 2219-2228, 2005.

Park, K., Chow, J. C., Watson, J. G., Trimble, D. L., Doraiswamy, P., Park, K., Arnott, W. P., Stroud, K. R., Bowers, K., and Bode, R.: Comparison of continuous and filter-based carbon measurements at the Fresno Supersite, J. Air Waste Manage., 56(4), 474-491, 2006.

Petzold, A., Kopp, C., and Niessner, R.: The dependence of the specific attenuation cross-section on black carbon mass fraction and particle size, Atmos. Environ., 31(5), 661-672, 1997.

Petzold, A., Schloesser, H., Sheridan, P., Arnott, W., Ogren, J., and Virkkula, A.: Evaluation of multiangle absorption photometry for measuring aerosol light absorption, Aerosol Sci. Technol., 39(1), 40-51, 2005.

Petzold, A. and Schönlinner, M.: Multi-angle absorption photometry - a new method for the measurement of aerosol light absorption and atmospheric black carbon, J. Aerosol Sci., 35(4), 421-441, 2004.
Rice, J.: Comparison of integrated filter and automated carbon aerosol measurements at Research Triangle Park, North Carolina, Aerosol Sci. Technol., 38(S2), 23-36, 2004.

Russchenberg, H., Bosveld, F., Swart, D., Ten Brink, H., de Leeuw, G., Uijlenhoet, R., Arbesser-Rastburg, B., Van der Marel, H., Ligthart, L., Boers, R., and Apituley, A. : Ground-based atmospheric remote sensing in the Netherlands: European outlook, IEICE Trans. Commun., Vol. E88-B, p. 6, 2005.

Saathoff, H., Naumann, K. H., Schnaiter, M., Schöck, W., Weingartner, E., Baltensperger, U., Krämer, L., Bozoki, Z., Pöschl, U., and Niessner, R.: Carbon mass determinations during the AIDA soot aerosol campaign 1999, J. Aerosol Sci., 34(10), 1399-1420, 2003.

Schaap, M., Apituley, A., Timmermans, R. M. A., Koelemeijer, R. B. A., and de Leeuw, G.: Exploring the relation between aerosol optical depth and $\mathrm{PM}_{2.5}$ at Cabauw, the Netherlands, Atmos. Chem. Phys., 9, 909-925, 2009, http://www.atmos-chem-phys.net/9/909/2009/.

Schmid, O., Artaxo, P., Arnott, W. P., Chand, D., Gatti, L. V., Frank, G. P., Hoffer, A., Schnaiter, M., and Andreae, M. O.: Spectral light absorption by ambient aerosols influenced by biomass burning in the Amazon Basin. I: Comparison and field calibration of absorption measurement techniques, Atmos. Chem. Phys., 6, 3443-3462, 2006, http://www.atmos-chem-phys.net/6/3443/2006/.

Schnaiter, M., Schmid, O., Petzold, A., Fritzsche, L., Klein, K. F., Andreae, M. O., Helas, G., Thielmann, A., Gimmler, M., and Möhler O.: Measurement of wavelength-resolved light absorption by aerosols utilizing a UV-VIS extinction cell, Aerosol Sci. Technol., 39(3), 249-260, 2005.

Seinfeld, J. H. and Pandis, S. N.: Atmospheric Chemistry and Physics, From Air Pollution to Climate Change, John Wiley \& Sons, Inc., New York, 1998.

Slowik, J. G., Cross, E. S., Han, J. H., Davidovits, P., Onasch, T. B., Jayne, J. T., Williams, L. R., Canagaratna, M. R., Worsnop, D. R., and Chakrabarty, R. K.: An inter-comparison of instruments measuring black carbon content of soot particles, Aerosol Sci. Technol., 41(3), 295-314, 2007.

Steiger, M.: An overview of Diesel and wood burning soot chamber experiments and a loading effect correction for Aethalometer measurements, Diploma thesis, ETH Zürich, Switzerland, 2008.

Subramanian, R., Roden, C. A., Boparai, P., and Bond, T. C.: Yellow beads and missing particles: trouble ahead for filter-based absorption measurements, Aerosol Sci. Technol., 41, 630-637, 2007.

Virkkula, A., Ahlquist, N., Covert, D., Arnott, W., Sheridan, P., Quinn, P., and Coffman, D.: Modification, calibration and a field test of an instrument for measuring light absorption by particles, Aerosol Sci. Technol., 39(1), 68-83, 2005a.

Virkkula, A., Ahlquist, N., Covert, D., Sheridan, P., Arnott, W., and Ogren, J.: A three-wavelength optical extinction cell for measuring aerosol light extinction and its application to determining light absorption coefficient, Aerosol Sci. Technol., 39(1), 52-67, 2005b.

Virkkula, A., Makela, T., Hillamo, R., Yli-Tuomi, T., Hirsikko, A., Hameri, K., and Koponen, I. K.: A simple procedure for correcting loading effects of aethalometer data, J. Air Waste Manage., 57(10), 1214-1222, 2007. 
Wallace, L.: Real-time measurements of black carbon indoors and outdoors: A comparison of the Photoelectric Aerosol Sensor and the Aethalometer, Aerosol Sci. Technol., 39(10), 1015-1025, 2005.

Weingartner, E., Nyeki, S., and Baltensperger, U.: Seasonal and diurnal variation of the aerosol size distribution $(10<\mathrm{D}<750 \mathrm{~nm})$ at a high alpine site (Jungfraujoch $3580 \mathrm{~m}$ a.s.1.), J. Geophys. Res., 104, 26809-26820, 1999.
Weingartner, E., Saathof, H., Schnaiter, M., Streit, N., Bitnar, B., and Baltensperger, U.: Absorption of light by soot particles: Determination of the absorption coefficient by means of Aethalometers, J. Aerosol Sci., 34, 1445-1463, 2003. 